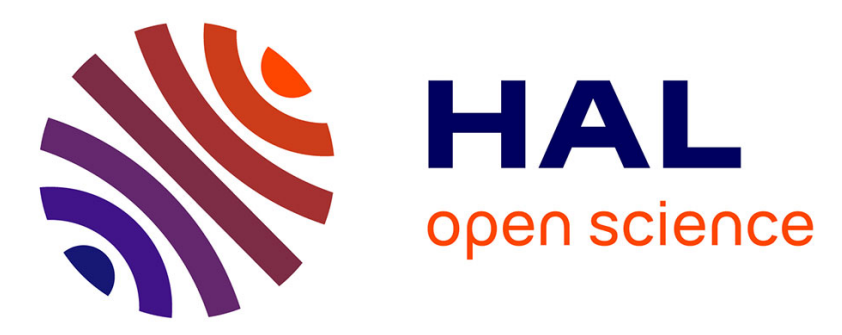

\title{
The tone patterns of numeral-plus-classifier phrases in Yongning Na: a synchronic description and analysis
}

Alexis Michaud

\section{To cite this version:}

Alexis Michaud. The tone patterns of numeral-plus-classifier phrases in Yongning Na: a synchronic description and analysis. Nathan Hill \& Tom Owen-Smith. Transhimalayan Linguistics. Historical and Descriptive Linguistics of the Himalayan Area, De Gruyter Mouton, pp.275-311, 2013, Trends in Linguistics. Studies and Monographs [TiLSM] 266, 978-3-11-031083-2. halshs-00821180v2

\section{HAL Id: halshs-00821180 \\ https://shs.hal.science/halshs-00821180v2}

Submitted on 5 Aug 2013

HAL is a multi-disciplinary open access archive for the deposit and dissemination of scientific research documents, whether they are published or not. The documents may come from teaching and research institutions in France or abroad, or from public or private research centers.
L'archive ouverte pluridisciplinaire HAL, est destinée au dépôt et à la diffusion de documents scientifiques de niveau recherche, publiés ou non, émanant des établissements d'enseignement et de recherche français ou étrangers, des laboratoires publics ou privés. 
Published in: Nathan Hill \& Tom Owen-Smith (eds.), Transhimalayan Linguistics.

Berlin: De Gruyter Mouton (2013), pp. 275-311.

\section{The tone patterns of numeral-plus-classifier phrases in Yongning Na: a synchronic description and analysis"}

\section{Alexis Michaud}

\section{Introduction}

Level-tone systems in the Sino-Tibetan family are now well-attested, and increasingly well-described (about Pumi, see Ding 2006 and Jacques 2011; about Hakha Lai: Hyman and VanBik 2002, 2004; see also the synthesis by Evans 2008). The present study aims to contribute to this strand of research by describing a specific area of the tonal morphology of the Yongning $\mathrm{Na}$ language, namely the tone patterns of its numeral-plus-classifier phrases. This is part of a broader endeavour to describe the entire tonal morphology of this language.

\footnotetext{
*Many thanks to Duan Bingchang 段炳昌, Wang Weidong 王卫东, Yang Liquan 杨立权 (Yunnan University) and Latami Dashi 拉他咪・达石 (Ninglang Research Centre in Ethnology) for making my fieldwork possible, and to the Na language consultants and friends, in particular Latami Dashilame 拉他咪・达石拉么. Many thanks to Yu Qian 于谦 for information on sandhi in Mandarin; to Séverine Guillaume for making the audio and electroglottographic data available online with their annotation in the Pangloss Collection; to Roselle Dobbs, Liberty Lidz and an anonymous reviewer for useful comments and suggestions; and to Jean-Michel Roynard for assistance with editorial matters. I alone am responsible for remaining shortcomings.

Fieldwork was partly funded by the Agence Nationale de la Recherche as part of the research projects PASQi ("What defines Qiang-ness? Towards a phylogenetic assessment of the Southern Qiangic languages of Muli", 2008-2012) and HimalCo (Parallel corpora in languages of the Greater Himalayas, 2013-2015). Finally, the present chapter is a contribution to the strand "Phonetic and phonological complexity" within the LabEx project "Empirical Foundations of Linguistics" (EFL, 2011-2020).
} 
Yongning $\mathrm{Na}$ (endonym: /na $\rfloor-\mathrm{z}_{\mathrm{w}} \mathrm{\gamma t} /$ ) ) is a member of the Naish subgroup of Sino-Tibetan, which also includes the Naxi and Laze languages (Guo Dalie and He Zhiwu 1994, 5-9; Jacques and Michaud 2011, Appendix 1). It is spoken in the plain of Yongning, Lijiang Municipality, China (Lìjiāng shì Nínglàng xiàn Yǒngníng xiāng 丽江市宁 蒗县永宁乡). A salient characteristic of this language is its complex tonal morphology, which is apparent from the first contact with the language, witness sentences (1) and (2) (from field notes):

(1)

$$
\begin{aligned}
& \text { njr-t bit-zot-ho」 } \\
& \text { nj } \gamma\rfloor \text { bit zo ho } \\
& \text { 1SG to_go OBLIGATIVE FUT(/DESIDERATIVE) }
\end{aligned}
$$

$$
\begin{aligned}
& \text { njrł zi」-bi」-zo」-ho } \\
& \text { njr」 zi」 bi- zo ho } \\
& \text { 1SG to take to go OBLIGATIVE FUT(/DESIDERATIVE) } \\
& \text { "I have to go and take [my luggage] now." }
\end{aligned}
$$

The difference in the lexical tone on the main verb - in (1): /bit/ 'to go', Mid tone; in (2): /zi J/ 'to take', Low tone - is reflected in the tones of the following syllables, all the way to the end of the sentence. Such phenomena permeate numerous aspects of the morphosyntax of Yongning $\mathrm{Na}$; a detailed description is called for.

Tonal alternations are best described in dialects where they are most widespread: an example from Sinitic languages

Tonal alternations in numeral-plus-classifier phrases are not uncommon in East/Southeast Asian languages. But in quite a few cases, these phenomena are so marginal as to become elusive. For instance, Chao Yuen-ren reports tonal change from tone 1 to tone 2 for the Standard Mandarin numerals 'one', 'seven' and 'eight' (一, 七, 八 ; Pinyin: $y \bar{l}, q \bar{l}, b \bar{a}$ ) before tone-4 classifiers: 一件, 七件 and 八件 (' 1 ', '7' and ' 8 ' with the classifier for items/articles) are realized as yí jiàn, qí jiàn and bá jiàn, not *yì jiàn, * qui jiàn and *ba jiàn (Chao Yuen-ren 1968, 571). However, this sandhi pattern has now receded. Surveys involving a total of more than 300 speakers were conducted in the 1980s; they show a considerable generation gap, with no speaker under age 34 having sandhi for ' 7 ', and only about $5 \%$ of the same age group having sandhi for ' 8 ' (Hu Mingyang 1997; this 
sandhi pattern has now been officially removed from Standard Mandarin as defined by the People's Republic of China). The figures suggest that the evolution was not identical for the two numerals, despite their identical lexical tone: sandhi for ' 8 ' seems more resilient to change. In the 1980s, averaging across age groups about $40 \%$ of speakers still realized the tone sandhi for ' 8 ', versus less than $25 \%$ for ' 7 ' (same source as above). On the other hand, sandhi for ' 1 ' remains, so that speakers now say yi jiàn (with tone change) but qī jiàn and ba jiàn (without change).

The origin of this phenomenon is not easy to investigate. Not all the numerals that have the same tone (for tone 1: ' 1 ', ' 3 ', ' 7 ', ' 8 ') behave similarly. The fact that only ' 1 ', ' 7 ' and ' 8 ' partake in the alternation in the dialect described by Chao Yuen-ren, and only ' 1 ' in present-day Beijing Mandarin, must be attributed to dialect mixture, or described as remnants of an earlier pattern that used to be regular and phonetically motivated. In such a situation, one hopes to come across a dialect that has a symmetrical, full-fledged system of regular tonal alternations, which can in turn shed light on the vestigial or borrowed alternations found in other dialects. For Mandarin, the place to look for seems to be dialects spoken in the Northeast and in the Central Plains, where sandhi is indeed attested for the four numerals that have the same lexical tone: ' 1 ', ' 3 ', '7', ' 8 ', thus pronouncing yí jiàn, sán jiàn, qí jiàn and bá jiàn for 一件, 三件, 七件 and 八件 (Qian $\mathrm{Yu}$, p.c.). This systematic sandhi pattern, also found in the vicinity of Beijing, presumably influenced Beijing Mandarin without being adopted in full. Evidence for dating this phenomenon comes from reconstructions of Middle Chinese. These four numerals are reconstructed as *2jit, *sam, $*_{\text {ts }}^{\text {h }}$ it and *pet, respectively (Baxter 2000, 2, 107, 118, 161), i.e. as a nonhomogeneous set: three of these have a final stop, whereas ' 3 ' with its nasal final is a conspicuous odd-man-out. This suggests that the tone sandhi does not predate the formation of the tonal category in which all four numerals now belong, and could, in fact, be much more recent.

Within the small group of Naish languages, tonal alternations in numeral-plus-classifier phrases are vestigial in Naxi (as spoken in the plain of Lijiang, Yunnan, China), limited in Laze (spoken in the neighbouring prefecture of Liangshan, Muli county; see Huang Bufan 2009; Michaud 2009; Michaud and Jacques 2012), and ubiquitous in Yongning Na, making the latter a fascinating object for study. As a first sample, consider the diversity of tones found on classifiers in: /nit-ni // 'two days', /so」-ni」]//

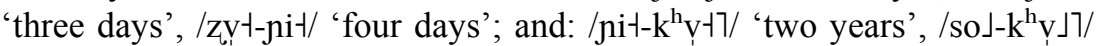
'three years', /zy $\left.-1-k^{\mathrm{h}} \mathrm{v}\right\rfloor /$ 'four years'. A previous study (Michaud 2011) 
brought out similarities between $\mathrm{Na}$, Naxi and Laze in the tone patterns of their numeral-plus-classifier phrases. As the objective of the 2011 study was to pursue the phylogenetic implications of these similarities, only limited detail was provided on the synchronic facts for Yongning Na. The aim of the present study, on the other hand, is to attempt a complete synchronic description and analysis.

\section{Background: The tone system of Yongning Na}

This section presents the tone system of Yongning $\mathrm{Na}$, as a background to the analysis of the tones of numeral-plus-classifier phrases. This presentation is organized in analytical order. It starts out from a static inventory of tone patterns over domains of different lengths, and gradually progresses towards an analysis - the same process that will be applied below to numeral-plus-classifier phrases. This mode of exposition replicates the progression of analysis during fieldwork, working up from the surface facts; this is intended to allow the reader to evaluate the analysis step by step, and to reflect on possible alternatives. Attention focuses on nouns, since this part of the tone system is the most relevant to the analysis of numeral-plus-classifier phrases.

\subsection{A static inventory of tone patterns for nouns}

Words said in isolation are what one starts out from in the earliest stages of fieldwork. Table 1 presents an overview of the tone patterns over monosyllabic nouns said in isolation. It was not possible to find a minimal set (words distinguished solely by tone) due to the relatively low number of monosyllabic nouns in the language.

Table 1. Tone patterns attested over monosyllabic nouns said in isolation

\begin{tabular}{lll}
\hline phonetic realization & label & example \\
\hline non-rising, non-low & M & zwæ- 'horse' \\
low-rising & LM & boJt 'pig' \\
mid-rising & MH & $\mathrm{ts}^{\mathrm{h}}$ æ- 7 'deer' \\
\hline
\end{tabular}

The second column of Table 1 proposes an analysis of the three patterns into level tones: L(ow), M(id), H(igh), and their combinations. Justification 
for this analysis comes from morpho-phonological alternations in which the tones partake; pieces of evidence will be provided in the course of the analysis. At an initial stage, the essential information is that provided in the leftmost column in Table 1, describing the three patterns in so many words as follows: a non-rising, non-low pattern; a low-rising pattern; and a midrising pattern.

The restrictions on the tones of monosyllables said in isolation are the following. (i) There are no examples of falling contours. (ii) There is no opposition between a high tone and a mid tone: only one type of non-low, non-rising tone is observed. Its realizations occupy the entire upper part of the tonal space, varying from mid to high, with a flat or falling contour. The choice of the label $\mathrm{M}$ (rather than $\mathrm{H}$ ) for this pattern will be explained further below, at the stage of phonological analysis. (iii) There is only one contour that starts on a low pitch. Using level-tone labels, this observation can be phrased as follows: there is no opposition between LM and LH.

The surface patterns are the same for other word classes, such as verbs.

Over disyllabic nouns, seven patterns are observed, as shown in Table 2.

Table 2. Tone patterns attested over disyllabic nouns said in isolation

\begin{tabular}{|c|c|c|c|}
\hline $1^{\text {st }}$ syllable & $2^{\text {nd }}$ syllable & label & example \\
\hline non-low & low & M.L & /datji」/ 'mule' \\
\hline non-low & low-rising & *M.LM & $*$ \\
\hline non-low & mid-rising & M.MH & /hwr-li-17/ 'cat' \\
\hline non-low & mid & M.M & /potlot/ 'ram' \\
\hline non-low & high & M.H & /hwæ-tşæ $7 /$ 'squirrel' \\
\hline low & low & ${ }^{*} \mathrm{~L} . \mathrm{L}$ & $*$ \\
\hline low & low-rising & L.LM & $\left.\left./ \mathrm{k}^{\mathrm{h}} \mathrm{v}\right\lrcorner \mathrm{mi}\right\lrcorner 7 /$ 'dog' \\
\hline low & mid-rising & L.MH & 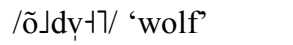 \\
\hline low & mid (or high) & L.M ( L.H) & /bo」mit//'sow' \\
\hline
\end{tabular}

Table 2 shows all logical possibilities; those that are not attested have a star $\left(^{*}\right)$ in the example and label columns. If the tone of the first syllable is non-low, there are four tonal possibilities on the second syllable: low; mid; high; or mid-rising. If the tone of the first syllable is low, there are three possibilities on the second syllable: low-rising; mid; or mid-rising.

The restrictions on the distribution of tones on disyllables can be described as follows. (i) Only two tones contrast on the first syllable: low 
and non-low. There can be no contour on the first syllable. (ii) A Mid tone cannot be followed by a low-rising tone. (iii) A disyllable cannot be low throughout, any more than a monosyllable. (iv) There is no contrast between a low + mid pattern and a low + high pattern; the notation adopted is L.M.

There are also strong limitations on tone patterns over three syllables: only twelve patterns are attested. The data in Table 3 are from trisyllabic nouns whose degree of lexical integration ranges from transparent compounds, such as 'Year of the Dragon', to fully undecomposable words, such as 'lips'. A hyphen is placed between the two parts of decomposable compounds.

Table 3. Tone patterns attested over trisyllabic nouns said in isolation

\begin{tabular}{|c|c|c|c|c|}
\hline $1^{\text {st }} \sigma$ & $2^{\text {nd }} \sigma$ & $3^{\text {rd }} \sigma$ & label & example \\
\hline non-low & mid & mid & M.M.M & dzr $-1 q^{h} w \gamma-1$ tset 'awl' \\
\hline non-low & mid & low & M.M.L & $\left.m y \lg ^{\prime} \dashv-\mathrm{k}^{\mathrm{h}} \mathrm{y}\right\rfloor$ 'year of the Dragon' \\
\hline non-low & mid & high & M.M.H & njo-bi-liך 'lips' \\
\hline non-low & mid & mid-rising & M.M.MH & by $-z y+-k^{h} y-17$ 'year of the Serpent \\
\hline non-low & low & low & M.L.L & mołjo」mi」 'owl' \\
\hline non-low & high & low & M.H.L & $æ-1 t s e\urcorner p^{h} æ 」$ 'kneebone' \\
\hline low & low & mid & L.L.M & $\left.\left.\mathrm{t}^{\mathrm{h}} \mathrm{o}\right\lrcorner \mathrm{k}^{\mathrm{h}} \mathrm{y}\right\lrcorner \mathrm{mi} \dashv$ 'male dog' \\
\hline low & low & low-rising & L.L.LM & dzu」na」mi」t 'wilderness' \\
\hline low & mid & mid & L.M.M & 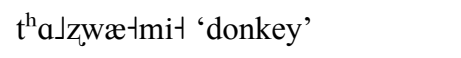 \\
\hline low & mid & high & L.M.H & æ」liłp $p^{\mathrm{h}} \mathfrak{\rceil}$ 'mirror' \\
\hline low & mid & mid-rising & L.M.MH & bi $\lrcorner p^{h} v^{h}-d z u-17$ 'flood' \\
\hline low & mid & low & L.M.L & bæ」bỵł-bỵ」 'ladybird' \\
\hline
\end{tabular}

Since there is a three-way opposition on the second syllable, the three terms are labelled as 'low', 'mid' and 'high', whereas for the first syllable the two terms are simply labelled 'low' and 'non-low'.

Some generalizations can be proposed in view of data from the three tables. The first generalization is that non-final syllables never carry a contour. The second is that the entire word (or phrase, or sentence) cannot carry low tone on all of its syllables. The third is that there can never be a trough: a tone surrounded by higher tones (non-low followed by low followed by mid, for instance). 
Data from Table 3 confirm the observation made in Table 2, that a mid (non-low) tone can be followed by one of four tones: low, mid, high, or mid-rising, whereas a low tone can only be followed by low-rising, mid or mid-rising. Additionally, the data from Table 3 suggest that a high tone can only be followed by a mid tone.

After this static inventory, a dynamic approach to the tones of nouns can be proposed.

2.2. A dynamic view, bringing out six underlying tonal categories for monosyllabic nouns, and eleven categories for disyllabic nouns

\subsubsection{Monosyllabic nouns}

It was mentioned above that there are three patterns for monosyllables said in isolation: low-rising; non-low; and mid-rising. The set of nouns realized as non-low in isolation is not homogeneous, however, witness the behaviour of /jot/ 'sheep', /zwæ-t/ 'horse' and /lat/ 'tiger', all of which are realized with a non-low tone in isolation.

In association with the copula, they yield: /jo $」 \mathrm{ni}\rfloor 7 /$ 'is (a/the) ram', with low tone on the noun; /zwæ- ni7/ 'is (a/the) horse', with mid tone on the noun, and high tone on the copula; and /la- ni $J /$ 'is (a/the) tiger', with mid tone on the noun and low tone on the copula. Since the morphosyntactic context is the same, these three words must be considered as representatives of three different lexical tones. These three tones all neutralize to mid (non-low) when the noun is said in isolation.

The set of nouns realized as low-rising in isolation is not homogeneous either: in some contexts, such as object+verb combinations, /zæ $\mathrm{Jt} /$ 'leopard' and /bo $H / /$ 'pig' have a different behaviour. For example, '... has bought leopards' is /zæ」 hwæ--ze J/, with a L tone on the accomplished suffix, whereas '... has bought pigs' is /bo」 hwæ- -ze-t/, with M tone on the suffix.

As an aside about the research method: needless to say, these combinations were elicited with the greatest care, and verified over several field trips; an appropriate context was devised with the help of the main consultant, e.g., for '... has bought leopards', imagining that a king sends out someone to purchase leopards from hunters. Examples found in recorded narratives confirm the patterns that were obtained through systematic elicitation. The data are gradually archived and made available 
online through the Pangloss Collection (currently at http://lacito.vjf.cnrs.fr/pangloss/index en.htm).

To sum up, out of the three surface patterns on monosyllables in isolation, one $(\mathrm{MH})$ corresponds to a single phonological set: all the words realized with $\mathrm{MH}$ tone in isolation have the same tone pattern in a given morphosyntactic context. The two others constitute the neutralization of underlying patterns: LM corresponds to two underlying categories, and $\mathrm{M}$ to three categories. A dynamic view thus brings out six tonal categories of monosyllables.

The same approach is applied below to disyllables. The phonological nature of the categories will then be analyzed.

\subsubsection{Disyllabic nouns}

The same procedure as above was also applied to disyllabic nouns: looking at the behaviour of nouns in different morphosyntactic contexts, in order to find out how many tone classes need to be distinguished.

It was realized that the nouns realized with a M.M pattern in isolation make up two distinct sets: one after which the copula carries L tone; and one after which the copula carries $\mathrm{H}$ tone. One set is illustrated by /potlot/ 'ram', /potlot niJ/ 'is (a/the) ram'. The other is illustrated by /zwałzot/ 'colt', /zwæłzoł ni / / 'is (a/the) colt'.

Likewise, the nouns realized with a M.M pattern in isolation make up

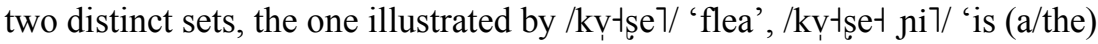
flea', the other by /hwæ-tsæ $7 /$ 'squirrel', /hwæ-tsæ $7 \mathrm{ni} J /$ 'is (a/the) squirrel'.

Finally, the nouns realized with a L.M pattern in isolation fall into no less than three categories. These three categories are brought out by intersecting evidence from two contexts: with a following copula, and with a following possessive, as shown in Table 4.

Table 4. Examples illustrating the existence of three tone categories neutralized to L.M in isolation

\begin{tabular}{|c|c|c|c|}
\hline in isolation & gloss & with copula & with possessive \\
\hline bo $\lrcorner \mathrm{mi}-1$ & sow & bo」mi-1 ni」 & bo」mi--by- \\
\hline bo $\downarrow 4 a-1$ & boar & bo」tał ni」 & bo」ta--by」 \\
\hline na」hĩ & Naxi & na」hĩ j niך & na」hĩt-bỵt \\
\hline
\end{tabular}

Addition of the copula sets apart a class exemplified by 'Naxi', after which the copula receives $\mathrm{H}$ tone. Addition of the possessive sets apart a 
class exemplified by 'boar', which depresses the tone of the possessive to $\mathrm{L}$, as opposed to its realization as $\mathrm{M}$ for the other words. While the evidence used to bring out the tone classes is morphotonological - looking at the behaviour of nouns in context -, the tone classes must be described as lexical, since the difference in the surface-phonological tone strings shown in Table 4 must be ascribed to a difference between the lexical items at issue, and hence, to a difference in lexical tone category.

In total, this yields eleven tonal classes of disyllables.

\subsection{A phonological analysis of the tone categories of nouns}

A number of different tonal categories were brought out on the basis of their different behaviour in different morphosyntactic contexts. This raises an issue for the analysis of each category: it is advisable to progress from the simplest cases to the most complex, but the tone categories of the simplest units - monosyllabic nouns - can only be brought out by examining their combinations with various other morphemes, whose tones, at this stage, have not been analyzed either. In theory, this raises an issue of circularity. In practice, bootstrapping is often required when analyzing a new language variety: groping for a correct analysis by trial and mistake.

A step forward in the analysis of the tones of nouns was made possible by progress in the analysis of the tones of other morphemes: it was realized that the copula carried $\mathrm{L}$ tone, and that the possessive carried $\mathrm{M}$ tone (it can also be analyzed phonologically as toneless). On this basis, it became possible to propose a phonological analysis for each of the tones of nouns.

The two tonal categories of nouns illustrated by /lat ni $\mathrm{J} /$ 'is (a/the) tiger' and /zwæ- $\mathrm{ni} 7 /$ 'is (a/the) horse' were reanalyzed as follows. In the first case, the copula surfaces with its own lexical tone. 'Tiger' represents the simplest case, analyzed as having $\mathrm{M}$ tone: a phonological tone identical with the surface tone in this context. (The same analysis can be proposed for the category of disyllables illustrated by /potlot/ 'ram'.) In the second case, 'horse', the copula surfaces with a $\mathrm{H}$ tone which must be supposed to be projected onto it by the noun. 'Horse' exemplifies a tone category characterized by a $\mathrm{H}$ tone which can only surface on a following syllable: a floating $\mathrm{H}$ tone. Discussion of this phenomenon warrants a separate subsection. 


\subsubsection{A floating H tone}

The floating $\mathrm{H}$ tone is never realized on the word itself, and can only be realized after it. The case of 'colt', realized in isolation as /zwæłzo-t/, offers a neat opportunity to extend the analysis to disyllables. The $\mathrm{H}$ tone that appears in /zwæłzo- ji $7 /$ 'is (a/the) colt' is interpreted as reflecting the floating $\mathrm{H}$ tone lexically attached to the noun 'colt'.

Since this is the only type of $\mathrm{H}$ tone that may be lexically attached to a monosyllable, it appears convenient to transcribe it as a simple $\mathrm{H}$ tone on monosyllabic nouns in the glossary and in examples within this volume: e.g. 'horse' is transcribed as /zwæ7/. For disyllables, however, there is an opposition between this floating $\mathrm{H}$ tone and a word-final $\mathrm{H}$ tone (as in /hwæ-tsul// 'rat'). This complexity of syllabic anchoring makes it necessary to use a nonstandard symbol: a symbol not used in the International Phonetic Alphabet. The pound symbol \# was (arbitrarily) chosen to stand for the end of a lexical word, adopting notation as /z̧wæłzo\#7/.

To repeat this important point with another example, the \#H-tone word 'little brother' and the M-tone word 'little sister' have the same tonal pattern in isolation (M on both syllables: /gitzu-// 'little brother', /go-tmi-// 'little sister'), but the former yields /gi-zu- ni $7 /$ ' '... is little brother' (tone sequence: M.M+H), the latter /go $\dashv \mathrm{mi}-\mathrm{ji}\rfloor /$ '...is little sister' (tone sequence: $\mathrm{M} . \mathrm{M}+\mathrm{L})$. The analysis proposed is that 'little brother' has a final $\mathrm{H}$ tone which remains unassociated unless it can associate to a following syllable: a $\mathrm{H}$ tone that is floating at the end of the word. The association of this floating $\mathrm{H}$ tone requires specific morphosyntactic conditions. For instance, the possessive, as a clitic, is not a suitable host for a floating tone; it receives $\mathrm{M}$ tone (by default), and the $\mathrm{H}$ tone remains unassociated (and thus does not surface in the resulting pattern), hence /gitzut-bỵt/ '...of [a/the] little brother', tonally identical with /go-mi-t-by-// '... of [a/the] little sister'.

\subsubsection{Word-final and morphological-nucleus-final H tones}

It was mentioned above that the words 'squirrel' and 'flea', realized with a M.H pattern in isolation (as /hwæ-tsææ $7 /$ and $/ \mathrm{ky}-s \mathrm{e} 7 /$, respectively), had different underlying tones.

The former has a simple tonal behaviour: its $H$ tone attaches to the last syllable of the lexical word. This is where it appears in all contexts. Under 
the present analysis, the first syllable of the word receives a $M$ tone by default, yielding a surface-phonological M.H pattern.

The latter has a $\mathrm{H}$ tone that attaches to the last syllable of a unit which will be referred to here as the morphological nucleus. A further complexity is that this tone only surfaces if the last syllable in the morphological nucleus is an appropriate host. When a word carrying this tone is pronounced in isolation, the end of the lexical word is also the end of the morphological nucleus, and the $\mathrm{H}$ tone lands there, hence the surface tone sequence M.H: /kytsel/ 'flea'. When the noun is followed by the possessive, the $\mathrm{H}$ tone does not surface, because this clitic is not an appropriate host. The result is / kvı-șet-byt/ ' ...of (a/the) flea', with $\mathrm{M}$ tone on both syllables of the noun, and also, by default, on the possessive.

Another nonstandard symbol was devised to transcribe the boundary that is relevant to the attachment of this type of tone: the end of the morphological nucleus. Again in an arbitrary way, the dollar sign \$ was chosen to stand for this boundary.

To sum up, disyllabic (and polysyllabic) nouns with $\mathrm{H}$ tone must be divided into three categories: $\mathrm{H \#}, \mathrm{HH}$ and $\mathrm{H} \$$, depending on how the $\mathrm{H}$ tone manifests itself. A $\mathrm{H}$ tone on the last syllable of a disyllabic or polysyllabic noun may have different origins. It may be the realization of a High tone that is anchored to the end of the morphological nucleus (a tone transcribed as $\mathrm{H} \$$ ). Or it may be a High tone anchored to the last syllable of the lexical word: H\#. It is impossible to distinguish these in isolation, as both positions coincide. In order to find out the underlying tones of words, they have to be heard in various contexts. For nouns, these are: tone-group-final position (as when they are said in isolation); tone-group-internal position; and when followed by a toneless clitic such as the possessive. The lexical tone can be arrived at with certainty by matching up the behaviour of the word in these various contexts.

\subsubsection{L tones: existence of a repair phenomenon for all-L tone groups}

'Sheep', realized in association with the copula as /jo $\lrcorner \mathrm{ni}\lrcorner 7 /$, is a case where the noun's phonological tone is hypothesized to surface as such: a L tone. A slight complexity is that the copula surfaces with a rising tone. This makes sense in view of the exceptionless observation that an entire utterance cannot carry low tone on all of its syllables. The sequences $\mathrm{L}+\mathrm{L}$ (monosyllabic noun+copula) and L.L + L (disyllabic noun+copula) cannot surface as such, due to a general prohibition against all-L tone groups in 
$\mathrm{Na}$. The contour observed at the end of a sequence of $\mathrm{L}$ tones is interpreted as resulting from the post-lexical addition of an extra tone: a High tone, creating a rising contour. The same applies to the tonal class of disyllables exemplified by $\left.\left./ \mathrm{k}^{\mathrm{h}} \mathrm{y}\right\lrcorner \mathrm{mi}\right\lrcorner /$ / 'dog'.

\subsubsection{Contour tones: sequences of level tones on the same syllable}

As mentioned in the static overview presented earlier, there are no falling contours in Yongning Na: no syllables carrying tones HL, HM, or ML. Also, tone-group-initial $\mathrm{H}$ is never observed.

Rising contours, on the other hand, do exist. They are restricted to the last syllable of a tone group: a rising contour is never observed on a nongroup-final syllable. The two observed contours are M-to-H and L-to-H (the latter constituting the neutralization of LM and LH in the underlying phonological form).

The phonological behaviour of the MH contour is straightforward. When the word is tone-group-final, the contour is realized as such: a rising tone with a non-low starting-point, e.g. in / $/ \mathrm{s}^{\mathrm{h}} \mathfrak{x}-1 /$ 'deer' and /hwr-li-17/ 'cat'. (Note that when a word is pronounced in isolation, it constitutes a tone group on its own: the beginning of the word is also the beginning of the tone group, and the end of the word is the end of the tone group.) When there is a following syllable within the tone group, the MH contour unfolds, projecting its $\mathrm{H}$ part onto that syllable.

Unlike the floating High tone $(\# \mathrm{H})$, which cannot attach to a following clitic, the MH contour can unfold over any syllable. With the copula, this yields (again taking the same examples) $/ \mathrm{ts}^{\mathrm{h}} \mathfrak{x}-\mathrm{ni} 7 /$ 'is [a/the] deer' and

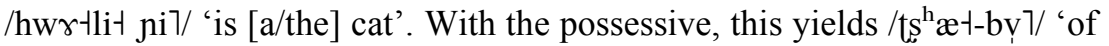
[a/the] deer' and /hwr-lit-bỵ// 'of [a/the] cat'.

\subsection{An overview}

This is not the place to provide a full treatment of the many interesting issues raised by the Yongning Na tone system; the above developments hopefully allow the reader to get a feel for the type of analytical challenges encountered in this language. Table 5 sets out a synthetic overview, presenting the six tone categories of monosyllabic nouns and the eleven categories of disyllabic nouns.

To date, no single morphosyntactic context bringing out all the tonal oppositions on nouns has been found: each context brings out only some of 
the oppositions, whereas others are neutralized. For instance, addition of the copula brings out the opposition between $\mathrm{M}$ and $\# \mathrm{H}$ tones $(\mathrm{M}+\mathrm{L}$ vs. $\mathrm{M}+\mathrm{H}$ for monosyllables, M.M $+\mathrm{L}$ vs. $\mathrm{M} . \mathrm{M}+\mathrm{H}$ for disyllables). This opposition is neutralized to $\mathrm{M}$ and M.M respectively in isolation. On the other hand, addition of the copula neutralizes the tonal contrasts that appear in isolation between $\mathrm{HH}, \mathrm{MH} \#$ and $\mathrm{H} \$$ on disyllables: all three yield $\mathrm{M} . \mathrm{M}+\mathrm{H}$ with the copula, whereas they are realized as M.M, M.MH and M.H respectively in isolation. So it is necessary to elicit a word in several contexts to determine its lexical tone. The table provides information on the tone categories (i) in isolation, (ii) when followed by the copula /ni J/ (in frame (3): see below), and (iii) when followed by the possessive clitic [bv-1], which carries $\mathrm{M}$ tone (and which may be phonologically analyzed as underlyingly toneless).

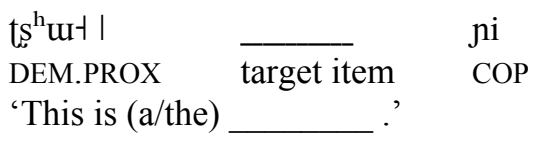

This set of three contexts is sufficient to bring out all oppositions, except that between LM and LH on monosyllables, which only surfaces in a very restricted number of contexts due to the general neutralization of LH and LM sequences at the surface-phonological level. (One such context is in association with the verb 'to buy': for instance, the LM-tone word 'pig' yields /bo」 hwæ--ze-/ '...bought pigs', whereas the LH-tone word 'leopard' yields /zæ」 hwæ--ze J/ '...bought leopards'.)

The tone of the proximal demonstrative [ts $\left.{ }^{\mathrm{h}} \mathrm{ut}\right]$ in (3) is $\mathrm{M}$, regardless of the tonal class of the following item; as a consequence, only the tonal pattern of the rest of the sentence is indicated in Table 5. On the other hand, no tone is indicated for the copula in frame (3), because its surface tone changes according to the tone category of the target-word.

Dots indicate boundaries between syllables within the lexical word, and the ' + ' sign indicates the boundary between the noun and a following morpheme. For instance, the information provided in Table 5 for disyllabic L-tone nouns is: L.LH in isolation, and L.L $+\mathrm{H}$ with copula and with possessive clitic. As an example, the word ' $\operatorname{dog}$ ' is $\left./ \mathrm{k}^{\mathrm{h}} \mathrm{y}\right\lrcorner \mathrm{mi} J 7 /$ in isolation, yielding $\left./ \mathrm{k}^{\mathrm{h}} \mathrm{v}\right\lrcorner \mathrm{mi} 」 \mathrm{ni} 7 /$ '...is [a/the] dog' and $\left.\left./ \mathrm{k}^{\mathrm{h}} \mathrm{v}\right\lrcorner \mathrm{mi}\right\lrcorner$-bv $7 /$ '...of [a/the] dog'.

The leftmost column in Table 5 ("analysis") presents the phonological categories. Examples are transcribed according to these categories, 
indicating tones at the end of the syllable using International Phonetic Alphabet tone-letters (Chao Yuen-ren 1930), e.g. /bo $J / /$ 'pig'. This is strictly equivalent to /bō/ in Africanist notation, or to other notations such as $/ \mathrm{bo}^{\mathrm{LM} /}$ or $/ \mathrm{L}^{\mathrm{LM}} \mathrm{bo} /$.

Table 5. The lexical tones of monosyllabic and disyllabic nouns.

\begin{tabular}{|c|c|c|c|c|c|c|}
\hline & analysis & in isolation & $+\mathrm{COP}$ & + POSS & example & meaning \\
\hline \multirow{6}{*}{$\begin{array}{l}\frac{\infty}{0} \\
\frac{\pi}{0} \\
\overline{\bar{\lambda}} \\
0 \\
0 \\
0 \\
0 \\
\Sigma\end{array}$} & LM & LH & $\mathrm{L}+\mathrm{H}$ & $\mathrm{L}+\mathrm{H}$ & boلt & pig \\
\hline & LH & LH & $\mathrm{L}+\mathrm{H}$ & $\mathrm{L}+\mathrm{H}$ & $z \mathfrak{l}$ & leopard \\
\hline & M & M & $\mathrm{M}+\mathrm{L}$ & $\mathrm{M}+\mathrm{M}$ & lat & tiger \\
\hline & $\mathrm{L}$ & M & $\mathrm{L}+\mathrm{LH}$ & $\mathrm{L}+\mathrm{M}$ & jo」 & sheep \\
\hline & $\# \mathrm{H}$ & M & $\mathrm{M}+\mathrm{H}$ & $\mathrm{M}+\mathrm{M}$ & z̧wæ7 & horse \\
\hline & MH\# & $\mathrm{MH}$ & $\mathrm{M}+\mathrm{H}$ & $\mathrm{M}+\mathrm{H}$ & $\left.\mathrm{ts}^{\mathrm{h}} \mathfrak{x}-1\right]$ & deer \\
\hline \multirow{11}{*}{ 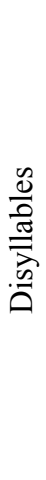 } & $\mathrm{M}$ & M.M & M.M+L & M.M+M & potlot & ram \\
\hline & $\# \mathrm{H}$ & M.M & M.M+H & M.M+M & z̧wæłzo\#† & colt \\
\hline & $\mathrm{MH \#}$ & M.MH & M.M+H & M.M+H & hwr-llit7 & cat \\
\hline & H\$ & M.H & M.M+H & M.M+M & kỵłșe $1 \$$ & flea \\
\hline & $\mathrm{L}$ & L.LH & L.L+H & L.L+H & $\left.\left.\mathrm{k}^{\mathrm{h}} \mathrm{Y}\right\rfloor \mathrm{mi}\right\rfloor$ & dog \\
\hline & L\# & M.L & M.L+L & M.L+L & $\mathrm{da}-\mathrm{ji}\rfloor$ & mule \\
\hline & $\mathrm{LM}+\mathrm{MH} \#$ & L.MH & L.M+H & L.M $+\mathrm{H}$ & $\tilde{\mathrm{o}}\lrcorner \mathrm{d}=\varphi^{-1}$ & wolf \\
\hline & $\mathrm{LM}+\# \mathrm{H}$ & L.M & L.M+H & L.M+M & na」hĩ \# & Naxi \\
\hline & LM & L.M & L.M+L & L.M+M & bo $\lrcorner \mathrm{mi}-1$ & sow \\
\hline & LH & L.H & $\mathrm{L} . \mathrm{H}+\mathrm{L}$ & L.H+L & bo」taך & boar \\
\hline & $\mathrm{H} \#$ & M.H & M.H+L & M.H+L & hwæ-tşæ 1 & squirrel \\
\hline
\end{tabular}

In light of this synthetic view, the distributional observations made above can be flipped around. For instance, instead of stating that $a$ monosyllabic noun that carries a $M$ tone when it is said in isolation may belong in one of three distinct underlying categories, it can now be said that the three non-contour lexical tones, $\mathrm{M}, \mathrm{L}$ and $\# \mathrm{H}$, all neutralize to [M] on monosyllables. Among disyllables, $\mathrm{M}$ and \#H neutralize to [M.M]; LM and $\mathrm{LM}+\# \mathrm{H}$ neutralize to [L.M]; and $\mathrm{H} \$$ and $\mathrm{H \#}$ neutralize to [M.H].

When the possessive clitic /by/ is added after a monosyllabic noun, yielding, for example, [bo」-bỵ] 'of the pig', contours unfold over the two syllables of the resulting combination: $\mathrm{LH}$ yields $\mathrm{L}+\mathrm{H}$ (as does LM, following neutralizing with $\mathrm{LH}$ ), and $\mathrm{MH}$ yields $\mathrm{M}+\mathrm{H}$. The non-contour tones, $\mathrm{M}, \mathrm{L}$ and $\# \mathrm{H}$, do not affect the possessive, which surfaces with default M. 
This last point offers crucial evidence for the distinction between contours (LM, LH and $\mathrm{MH \# )}$ on the one hand and the floating $\mathrm{H}$ tone $(/ \mathrm{HH} /)$ on the other. The second part of a contour is realized on the possessive; the floating $\mathrm{H}$ tone is not. The interpretation proposed is that the possessive clitic cannot provide anchorage for a tone, whereas it can host a tone level that is part of a tone anchored to a preceding syllable. The MH\# contour tone in Table 5 has a stable phonological anchorage: it is anchored to the syllable preceding the clitic. From there, the second part of the contour can be projected onto the possessive clitic - a process of contour unfolding which is distinct from processes of tonal anchoring. A schematic representation is presented below:
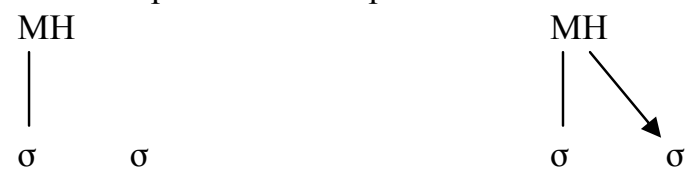

On the other hand, the floating $\mathrm{H}$ tone initially lacks anchorage, and the possessive clitic is unable to provide such anchorage. Since this $\mathrm{H}$ tone receives syllabic anchoring neither onto the word to which it is lexically attached, nor on the possessive clitic that follows it, it remains unassociated, and does not surface at all.

\subsubsection{Reflections on the structure of the system: phonological regularities or morphophonological oddities}

Looking back at the data in Table 5, it is tempting to look for phonological regularities that would account for all the observed data. The search for phonological regularities is soon up against sets of facts that resist phonological generalizations, however. For instance, there is no obvious reason why $\mathrm{L}$ should surface as $\mathrm{M}$ in isolation. This may have to do with the prohibition of all-L tone groups, and a fortiori all-L utterances; but for verbs this is remedied by adding a post-lexical final $\mathrm{H}$ tone, so that verbs with lexical L tone surface with a LH contour when they are said in isolation. If the tone system were based on a set of phonological rules rules applying uniformly in all morphosyntactic contexts -, lexical $\mathrm{L}$ on a noun would be expected to surface as LH, not as M. A similarly puzzling case is that of the L tone on disyllabic nouns. A word such as $\left./ \mathrm{k}^{\mathrm{h}} \mathrm{v}\right\lrcorner \mathrm{mi} J /$ ' $\operatorname{dog}$ ' yields $\left.\left./ \mathrm{k}^{\mathrm{h}} \mathrm{v}\right\rfloor \mathrm{mi}\right\rfloor \mathrm{J} / \mathrm{in}$ isolation, as expected, but when followed by the copula it yields $\left.\left./ \mathrm{k}^{\mathrm{h}} \mathrm{y}\right\lrcorner \mathrm{mi}\right\rfloor \mathrm{ni} / /$ 'is [a/the] dog': the copula loses its lexical L 
tone. There is no obvious reason why this should be so: one would have expected a $/{ }^{*}$ L.L.L/ sequence, realized as $\left.\left.\left./{ }^{*} \mathrm{k}^{\mathrm{h}} \mathrm{y}\right\rfloor \mathrm{mi}\right\rfloor \mathrm{ni}\right\rfloor 7 /$ following the addition of a post-lexical $\mathrm{H}$ tone to avoid an all-L phonological word.

This asymmetry in the tonal treatment of the copula after a L-tone noun, depending on the number of syllables in the noun, points to a crucial aspect of Yongning $\mathrm{Na}$ tone: many tone rules have narrowly restricted fields of application; they apply in highly specific morphosyntactic contexts, and are sensitive to the number of syllables (and internal makeup) of the morphemes at issue.

The key phonological facts are few in number; they can be summarized as follows. Within a tone group, contours are only realized as such in tonegroup-final position; in non-group-final position, the second level (the $\mathrm{H}$ portion in $\mathrm{MH}$, for instance) associates to the following syllable. $\mathrm{L}$ tone spreads progressively (left-to-right). All tones following $\mathrm{H}$ are lowered to L. Finally, $\mathrm{H}$ and $\mathrm{M}$ are neutralized to $\mathrm{M}$ in tone-group-initial position.

The points brought out in this introduction are central to the analysis of numeral-plus-classifier phrases presented below.

\section{Elicitation procedures}

All the data presented here were provided by one female consultant born in 1950 in the hamlet of /atlat-ьwr-/ (Chinese rendering: 阿拉瓦), in the Yongning plain, and who has lived there all her life, except for two years in the city of Lijiang, at the home of one of her sons. Her speaker code in the author's database of Naish languages is F4; our collaboration began in 2006. For each noun in the vocabulary list collected in the course of fieldwork ${ }^{1}$ (slightly above 800 ), a note was made of the classifiers typically associated with the noun (following the example of E. Henderson's dictionary of Bwe Karen [1997]). This obviously does not capture the full range of stylistic possibilities in the choice of classifiers, which are best studied from their actual use: "a noun can be accompanied by various classifiers depending on context, so that it may not be adequate to describe

1 The vocabulary list is available from the STEDT project (http://stedt.berkeley.edu/). About the classifiers of Yongning $\mathrm{Na}$, see also Lidz 2006, 8-14 and Lidz 2010, xxxiv-xxxv, 216-223, 232. Thomas Pinson's NaxiChinese-English glossary (Pinson 1998: 245-251) contains an inventory of comparable size: about 90 classifiers. 
one of those as fundamental at a lexical level" (François 2000, 167, my translation).

To the list of classifiers obtained through lexical elicitation were added measure words (inch, armspan, heap...) and time units (day, month, year...): the term "classifier" is understood here in the syntactic sense of any noun that may appear directly after a numeral. Table 1 presents the classifiers brought to light so far. The notation of tones is based on the system outlined above, as set out systematically in Michaud 2008 (with apologies for the recurring self-reference). The asterisk * after the tone category $\left(L^{*}, M^{*}, H^{*} \ldots\right)$ indicates defective classifiers, which only appear with the numeral ' 1 ': for instance, there exists a specific classifier for individuals, $/ \mathrm{y}-1$, appearing only after ' 1 ', ' ' 11 ', ' 21 ' etc, in complementary distribution with $/ \mathrm{kv}-17 /$. Numerals in the 'Tone' column (e.g. the ' 1 ' in 'L1') are explained in 5.2 below.

Table 1. A list of Yongning Na classifiers, by alphabetical order

\begin{tabular}{|c|c|c|}
\hline Classifier & Tone & Description \\
\hline æ」 & L1 & cl. for fires \\
\hline bæ- & M1 & cl. for sorts/types of things \\
\hline bæ」 & L1 & self-classifier for flowers \\
\hline br-17 & MH1 & cl. for scarves \\
\hline bi」 & L3 & self-classifier for animal hooves; also used for footprints \\
\hline bỵ $\lrcorner d z e\rfloor$ & $\mathrm{L}^{*}$ & a ladleful of \\
\hline si & $\mathrm{H} 2$ & one hundredth of a yuan, one penny \\
\hline ci $\rceil$ & H1 & 100 \\
\hline $\mathrm{da}-17$ & MH2 & self-classifier for blows (from the verb 'to strike') \\
\hline $\mathrm{d} \rightsquigarrow$ & L1 & section of (road); bolt of cloth \\
\hline di $\rfloor$ & L3 & self-classifier for plains \\
\hline do7 & $\mathrm{H} 1$ & cl. for partitions/walls \\
\hline $\mathrm{dv}\rfloor$ & $\mathrm{L}^{*}$ & cl. for a flock of cattle and a group of people \\
\hline dwæ 1 & $\mathrm{H} 1$ & cl. for steps (of stairs) \\
\hline dze & L1 & cl. for pairs of separable objects, e.g. a pair of bottles \\
\hline dzit & M2 & cl. for pairs of non-separable objects, e.g. a pair of shoes \\
\hline dzi」 & $\mathrm{L} 2$ & cl. for trees, bamboo \\
\hline dz̧u」 & L1 & cl. for spans of time \\
\hline dzuu」 & $\mathrm{H} 1$ & self-classifier for marketplaces/towns \\
\hline dzu & H1 & cl. for beams (in carpentry) \\
\hline
\end{tabular}




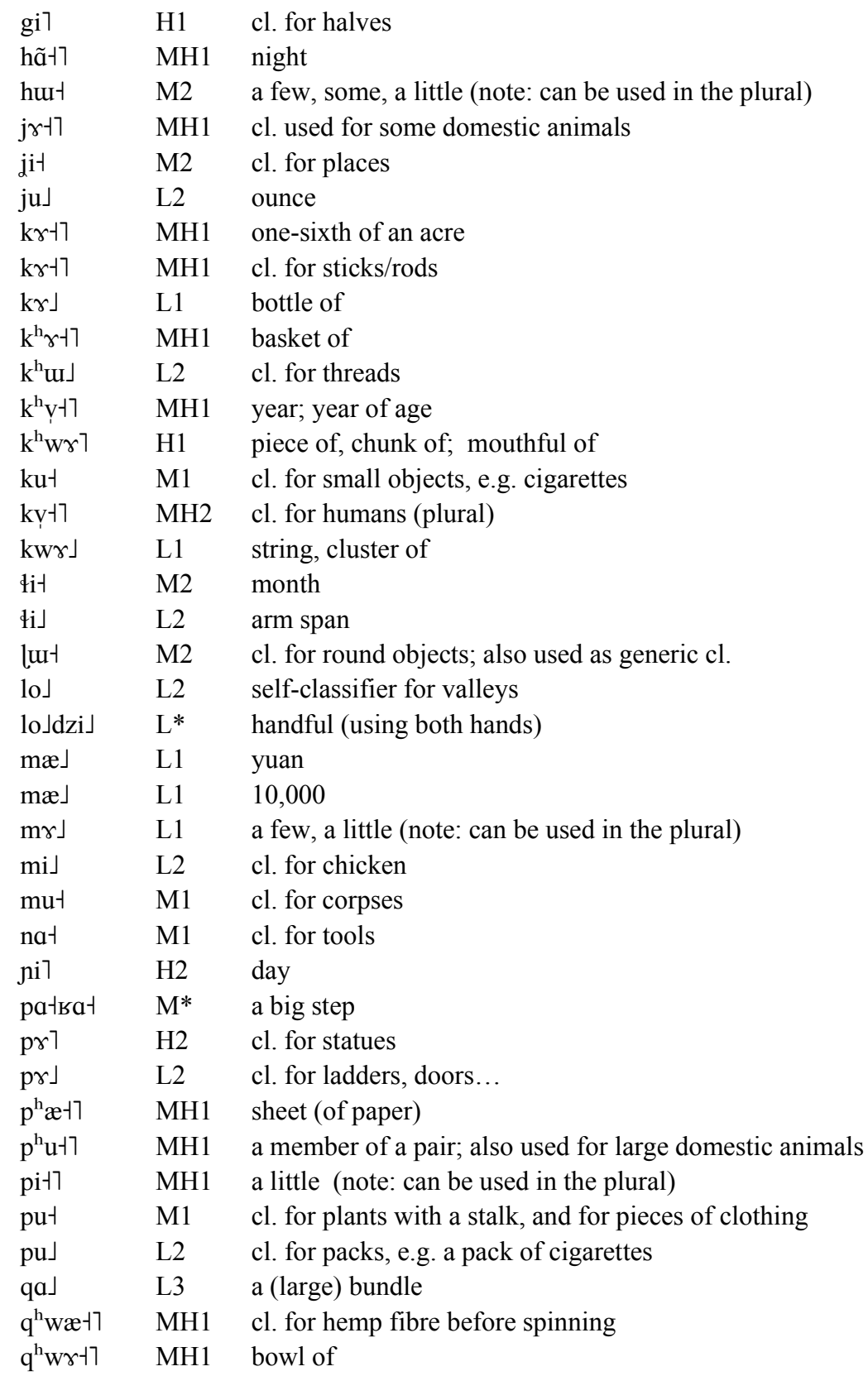




\begin{tabular}{|c|c|c|}
\hline$\tilde{f}^{\dagger}$ & M2 & cl. for families \\
\hline $\mathrm{Bu}\rfloor$ & $\mathrm{L} 2$ & sort of \\
\hline swrt & M1 & heap, e.g. of grains, of cut wood \\
\hline $\mathrm{sa}\rceil$ & $\mathrm{H}^{*}$ & a sort of; only used in the construction "there is not a thing" \\
\hline şæ-17 & MH1 & small bundle of cut cereal \\
\hline șu」 & L2 & times (doing something $n$ times) \\
\hline so」 & L1 & some, a few \\
\hline tat7 & MH1 & entirely, all; everyone (note: can be used in the plural) \\
\hline $\left.\operatorname{tc}^{\mathrm{h}} \mathrm{i}\right\rfloor$ & $\mathrm{L} 2$ & cl. for meals \\
\hline$\left.t c^{\mathrm{h}} \mathrm{u}\right\rfloor$ & $\mathrm{L}^{*}$ & in combination with 'one', means 'together' \\
\hline tçit & M1 & some, a few (note: can be used in the plural) \\
\hline tढ̣iłl & MH1 & cl. for loads carried by a pack-animal \\
\hline tçiłl & MH1 & pound of \\
\hline $\mathrm{t}^{\mathrm{h}} \mathrm{\gamma} \mathrm{T}$ & $\mathrm{H} 1$ & drop of (liquid) \\
\hline$t^{\mathrm{h}} \mathrm{v}-17$ & MH1 & cl. for steps (in walking) \\
\hline ti-17 & MH1 & cl. for layers (of dust etc) \\
\hline $\mathrm{ti \rceil}$ & H1 & handspan (between the thumb and index finger) \\
\hline to 7 & $\mathrm{H} 1$ & armful of \\
\hline to $」 \mathrm{pi}\rfloor$ & $\mathrm{L}$ & time ( $n$ times as many/much as...) \\
\hline tșæ-17 & MH1 & cl. for ears of corn \\
\hline $\mathrm{ts}^{\mathrm{h}} \mathrm{\gamma}-17$ & MH1 & cl. for cockscombs, leaves, and heads of garlic \\
\hline $\left.\mathrm{ts}^{\mathrm{h}} \mathrm{i}\right\rceil$ & $\mathrm{H} 1$ & cl. for animal skins \\
\hline $\left.\mathrm{ts}^{\mathrm{h}} \mathrm{i}\right\rfloor$ & L3 & cl. for roof parts \\
\hline tso」 & L3 & cl. for rooms \\
\hline tswrt & M1 & handful \\
\hline tỵt & M1 & one tenth of a yuan \\
\hline tỵt & M1 & 1,000 \\
\hline ty」 & $\mathrm{L} 2$ & large chunk of \\
\hline ỵ & $\mathrm{H} 2$ & self-classifier for pots \\
\hline $\mathrm{y}^{-1}$ & $M^{*}$ & cl. for one individual (human) \\
\hline wr」 & $\mathrm{L} 2$ & cl. for generations \\
\hline wr」 & L2 & load, charge, weight \\
\hline wu」 & L2 & cl. for teams (of oxen) \\
\hline$z \gamma\rfloor$ & L3 & cl. for lines/patterns (in weaving, drawing etc) \\
\hline
\end{tabular}

Establishing the underlying tonal categories was not a straightforward task, because the tone of the classifier is affected by the numeral with which it is associated, witness the examples cited above: /dut-ni $7 /$ 'one day', /ni--ni7/ 'two days', /so」-ni」7/ 'three days', /zył-ni-// 'four days'; 


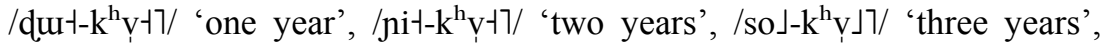
$\left.\mid z \mathrm{z} y-\mathrm{k}^{\mathrm{h}} \mathrm{y}\right\rfloor /$ 'four years'. The first step consisted of conducting systematic elicitation, to find out how many tonal categories there were. A first data set was elicited in 2009, covering the range of numerals from 1 to 30 , and a second set in 2011, covering the range from 1 to 100 and including more classifiers.

Elicitation yielded less than fully consistent results, due in part to the unusual nature of the counting task for the consultant. Although familiar with the process of linguistic elicitation, she easily became confused when counting all the way from 1 to 30 or 100 . One and the same combination was realized in different ways during different elicitation sessions. When such discrepancies were pointed out to the consultant, she would identify one pattern as correct and reject the others as mistaken. However, these $a$ posteriori judgments also wavered: a variant that had been brushed aside as mistaken would come up again in a later session, and the consultant would then insist that it was correct. Initially, I wrongly assumed that only one tone pattern could be correct: it gradually became clear that there exist two variants for some of the phrases. For instance, the association of '47' with

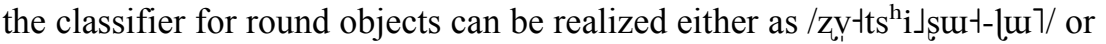
as /zy $\left./ t^{h} i\right\rfloor s u J-\mid w J /$. (Variants like this one are discussed in Section 5.1; to preview the result of analysis: in the first variant, the phrase is parsed into two tone groups, whereas in the second, it is parsed as a single tone group.) Taking into account these two factors - that occasional mistakes are not uncommon in systematic elicitation, and that two variants can both be correct -, a comprehensive description could finally be arrived at.

The entire set of transcribed recordings is available online, with both a surface-phonological transcription and an indication of the underlying tonal pattern. Some technical details are presented in the next paragraphs.

\section{Recordings}

In 2009 the recordings were in stereo, collecting the signal from two microphones: a head-mounted Sennheiser HSP 2, and an AKG C-900. In 2011, an electroglottographic signal was collected simultaneously with the audio from the head-mounted microphone. The electroglottographic signal allows for a high-precision measurement of the voice's fundamental frequency (as well as of other glottal parameters; about electroglottography, see the initial report of the invention: Fabre 1957; a synthesis: Baken 1992; 
some caveats: Orlikoff 1998; discussions about parameters that can be measured: Henrich et al. 2004, Michaud 2004; and applications to the study of specific linguistic issues, e.g. Brunelle et al. 2010).

A total of 2,810 numeral-plus-classifier phrases were recorded, divided into 41 files, 28 of which have an electroglottographic component. In the recordings that extend from 1 to 100, the intervals [50..59] and [80..89] were not recorded, because previous elicitation had shown that their tone patterns were identical with those of [40..49] and [60..69], respectively, and shortening the list of numerals reduced consultant fatigue.

The entire set is available online from the Pangloss Collection (about which see Michailovsky, Michaud, and Guillaume 2011, and Michaud et al. 2012), synchronized with transcriptions in English, Chinese and French. The current address is http://lacito.vjf.cnrs.fr/archivage/index_en.htm; the Yongning Na data can be accessed - directly from $\mathrm{http} / / /$ lacito.vjf.cnrs.fr/archivage/languages/Na_en.htm (see Figures 1 and 2). These documents are perennially archived and will continue to be accessible even when the above addresses eventually change.

\begin{tabular}{|c|c|c|c|c|}
\hline \multicolumn{5}{|c|}{ H1 category of classifiers } \\
\hline \multirow[t]{2}{*}{$\begin{array}{l}\text { classifier } \\
\text { for... }\end{array}$} & \multicolumn{2}{|c|}{$\begin{array}{l}\text { recordings WITH electroglottographic } \\
\text { component }\end{array}$} & \multicolumn{2}{|c|}{$\begin{array}{l}\text { recordings WITHOUT electroglottographic } \\
\text { component }\end{array}$} \\
\hline & 30 to 100 & 1 to 100 & 1 to 10 & 1 to 30 \\
\hline chunks & $\underline{A U D I O}+\underline{E G G}$ & 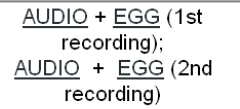 & & $\underline{\text { AUDIO }}$ \\
\hline trees & & & $\underline{\text { AUDIO }}$ & \\
\hline
\end{tabular}

\begin{tabular}{|c|c|c|c|}
\hline \multicolumn{4}{|c|}{ H2 category of classifiers } \\
\hline \multirow[t]{2}{*}{$\begin{array}{l}\text { classifier } \\
\text { for... }\end{array}$} & \multicolumn{2}{|c|}{$\begin{array}{l}\text { recordings WITH electroglottographic } \\
\text { component }\end{array}$} & \multirow{2}{*}{$\begin{array}{c}\text { recordings WITHOUT electroglottographic } \\
\text { component }\end{array}$} \\
\hline & 30 to 100 & 1 to 100 & \\
\hline days & $\underline{\mathrm{AUDIO}}+\underline{\underline{E G G}}$ & $\underline{\mathrm{AUDIO}}+\underline{\underline{E G G}}$ & $\underline{\text { AUDIO }}$ \\
\hline \multicolumn{4}{|c|}{ M1 category of classifiers } \\
\hline $\begin{array}{c}\text { classifier } \\
\text { for... }\end{array}$ & \multicolumn{2}{|c|}{$\begin{array}{l}\text { recordings WITH electroglottographic } \\
\text { component }\end{array}$} & $\begin{array}{l}\text { recordings WITHOUT electroglottographic } \\
\text { component }\end{array}$ \\
\hline
\end{tabular}

Figure 1. Screen shot showing how the list of resources is presented on the web interface 


\begin{tabular}{|c|c|c|c|c|c|c|}
\hline ऐ) & $\sum_{A}$ & 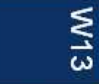 & $\varliminf_{N}$ & $\leqq$ & $\varliminf_{0}$ & $\S$ \\
\hline$\nabla \square$ & $\nabla \square$ & 回 & $\nabla \square$ & $\nabla \square$ & $\nabla \square$ & $\nabla \square$ \\
\hline 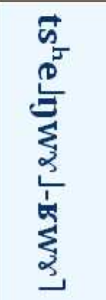 & 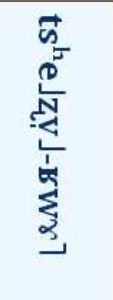 & 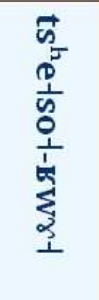 & 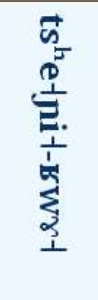 & 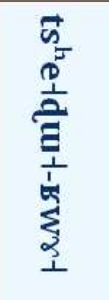 & 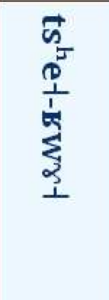 & 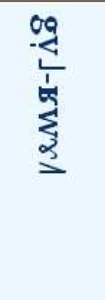 \\
\hline $\begin{array}{c}\overrightarrow{\mathrm{v}} \\
\mathrm{u}\end{array}$ & 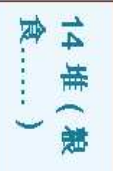 & 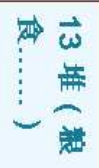 & $\underbrace{\vec{N}}$ & 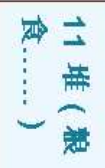 & 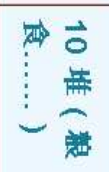 & 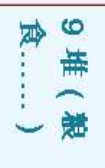 \\
\hline 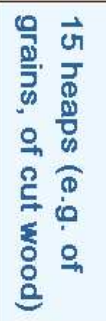 & 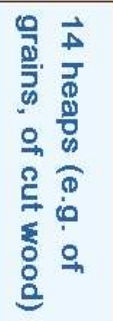 & 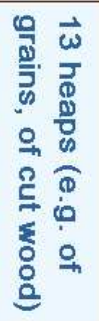 & 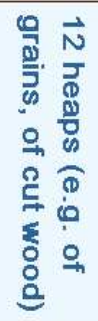 & 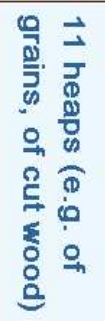 & 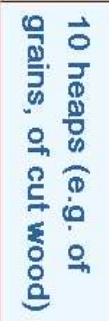 & 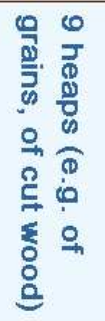 \\
\hline 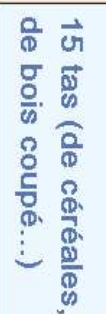 & 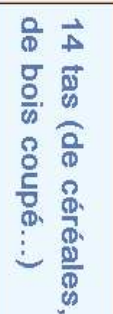 & 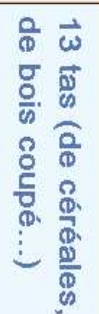 & 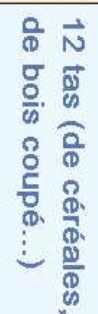 & 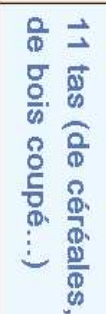 & 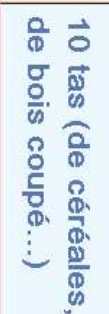 & 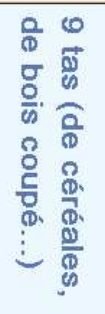 \\
\hline
\end{tabular}

Figure 2. A passage from one of the documents as displayed on the web interface. 
The availability of these audio and electroglottographic data with synchronized transcriptions makes it possible to get a feel for the data; it also opens perspectives for further research into a broad range of phonetic topics. Given the amount of time that is necessary to produce a state-of-theart experimental phonetic investigation, it is simply impossible for linguists who are working at the description of an entire language (or of several languages) to launch into a phonetic study to substantiate and refine each of their observations; on the other hand, it appears feasible to collect a sufficient amount of data for interested colleagues to conduct such a study. ${ }^{2}$

No amount of continuous speech would be enough to obtain all the numeral-plus-classifier combinations from 1 to 100 , hence the choice to resort to systematic elicitation. However, some of the combinations are

\footnotetext{
${ }^{2}$ Here are two examples (among many others) of phonetic phenomena that can be studied in future on the basis of the Yongning Na data:

(i) The implementation of tone. The electroglottographic signal was not exploited in the present study, except for its occasional use in auditory verification (the pitch can be clearer when listening to the electroglottographic signal than when listening to the audio). This signal could serve in future for a phonetic study of the implementation of tone in Yongning $\mathrm{Na}$. There is a large gap between phonological representations in terms of sequences of level tones, on the one hand, and observed fundamental frequency curves, on the other: "both $\mathrm{F}_{0}$ height and $\mathrm{F}_{0}$ velocity are relevant parameters (...) even for the simplest level tone languages" (Yu 2010, 1). A study of the implementation of tone sequences in $\mathrm{Na}$ would be a useful addition to the existing literature on contextual tonal variation and segmental effects on tone, as studied e.g. by Abramson 1979, Gsell 1985 and Gandour and Potisuk 1992 for Thai, and Xu Yi 1997, 1998 for Mandarin.

(ii) The weakened (hypo-articulated) realization of repeated words. When a consultant pronounces a sequence of numeral-plus-classifier phrases, such as /dut-

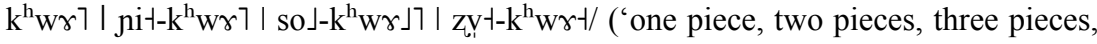
four pieces...'), the tone of the classifier changes (High, High, Low-to-High, Mid...) but its consonants and vowels do not. As a result, the speaker's attention focuses on the realization of the new information (essentially: the correct tone sequence for the phrase); in terms of the continuum from hyper-articulation to hypo-articulation (Lindblom 1990), the classifier is hypo-articulated. Specifically, the unvoiced lateral / $\mathrm{A} / \mathrm{in}$ classifiers such as / $\mathrm{i}-\mathrm{t} /$ 'month' and / $\mathrm{H} \mathrm{i} /$ 'armspan' is occasionally realized as voiced, despite the existence of a voicing opposition between $/ 4 /$ and $/ 1 /$ in Na. Pursuing such observations would shed light on the field of allophonic dispersion of $\mathrm{Na}$ phonemes. Due to the nature of the corpus, numerous tokens of each numeral and classifier are available, offering a good basis for statistical treatments.
} 
attested in the narratives with transcriptions, glosses and translations that are also available online from the Pangloss Collection.

\section{Results}

\subsection{A summary of the results}

A summary of all the results is presented in Table 2, which contains, in tightly packed form, the information necessary to generate the surfacephonological tone patterns of all numeral-plus-classifier phrases in Yongning Na. The mass of information presented in this table may seem staggering; were it not for the clear evidence from recorded data (presented in the previous section), one could suspect that this multiplicity of tone patterns is an artefact of elicitation procedures.

As in Table 1, the tonal labels for the nine categories anticipate the results of the analysis presented further below. Variants are separated by a slash (/). For typographical reasons, the table is divided into two halves: the $\mathrm{H}$ and $\mathrm{MH}$ tones $(\mathrm{H} 1, \mathrm{H} 2, \mathrm{MH} 1$ and $\mathrm{MH} 2)$ in a first table, and the $\mathrm{M}$ and $\mathrm{L}$ tones (M1, M2, L1, L2 and L3) in a second table. 
Table 2. The underlying tone patterns of the nine categories of numeral-plusclassifier phrases of Yongning Na, for all numerals from 1 to 100 .

Part 1: $\mathrm{H}$ and $\mathrm{MH}$ tones.

\begin{tabular}{|c|c|c|c|c|}
\hline & $\mathrm{H} 1$ & $\mathrm{H} 2$ & MH1 & MH2 \\
\hline 1 & $\mathrm{H} \$$ & HS & MH\# & MH\# \\
\hline 2 & $\mathrm{H} \$$ & H\$ & $\mathrm{MH} \#$ & $\mathrm{MH} \#$ \\
\hline 3 & $\mathrm{~L}$ & $\mathrm{~L}$ & $\mathrm{~L}$ & $\mathrm{~L}$ \\
\hline 4 & $\# \mathrm{H}$ & $\# \mathrm{H}$ & L\# & $\mathrm{L}$ \\
\hline 5 & $\# \mathrm{H}$ & $\# \mathrm{H}$ & L\# & $\mathrm{L}$ \\
\hline 6 & $\mathrm{H} \$$ & H\$ & $\mathrm{H \#}$ & $\mathrm{H} \$$ \\
\hline 7 & $\# \mathrm{H}$ & $\# \mathrm{H}$ & MH\# & MH\# \\
\hline 8 & $\mathrm{H} \$$ & H\$ & $\mathrm{H \#}$ & $\mathrm{H} \$$ \\
\hline 9 & $\# \mathrm{H}$ & $\# \mathrm{H}$ & L\# & $\mathrm{L}$ \\
\hline 10 & $\mathrm{~L}$ & $\mathrm{~L}$ & $\mathrm{~L}$ & $\mathrm{~L}$ \\
\hline 11 & $\mathrm{~L}$ & $\mathrm{~L}$ & $\mathrm{~L}$ & $\mathrm{~L}$ \\
\hline 12 & $\mathrm{~L}$ & $\mathrm{~L}$ & $\mathrm{~L}$ & $\mathrm{~L}$ \\
\hline 13 & $\mathrm{~L}$ & $\mathrm{~L}$ & $\mathrm{~L}$ & $\mathrm{~L}$ \\
\hline 14 & $\mathrm{~L}+\mathrm{H} \$$ & $\mathrm{~L}$ & $\mathrm{~L}+\mathrm{H} \#$ & $\mathrm{~L}+\mathrm{H} \#$ \\
\hline 15 & $\mathrm{~L}+\mathrm{H} \$$ & $\mathrm{~L}$ & $\mathrm{~L}+\mathrm{H} \#$ & $\mathrm{~L}+\mathrm{H} \#$ \\
\hline 16 & $\mathrm{~L}+\mathrm{H} \$$ & $\mathrm{~L}$ & $\mathrm{~L}+\mathrm{H} \#$ & $\mathrm{~L}+\mathrm{H} \#$ \\
\hline 17 & $\mathrm{~L}$ & $\mathrm{~L}$ & $\mathrm{~L}$ & $\mathrm{~L}$ \\
\hline 18 & $\mathrm{~L}+\mathrm{H} \$$ & $\mathrm{~L}$ & $\mathrm{~L}+\mathrm{H} \#$ & $\mathrm{~L}+\mathrm{H} \#$ \\
\hline 19 & $\mathrm{~L}+\mathrm{H} \$$ & $\mathrm{~L}$ & $\mathrm{~L}+\mathrm{H} \#$ & $\mathrm{~L}+\mathrm{H} \#$ \\
\hline 20 & $\# \mathrm{H}$ & $\# \mathrm{H}$ & MH\# & MH\# \\
\hline 21 & $\mathrm{H} \$$ & HS & MH\# & $\mathrm{MH} \#$ \\
\hline 22 & $\mathrm{H} \$$ & $\# \mathrm{H}$ & $\mathrm{MH} \#$ & MH\# \\
\hline 23 & ${ }^{\circ} \mathrm{L}$ & ${ }^{\circ} \mathrm{L}$ & ${ }^{\circ} \mathrm{L}$ & ${ }^{\circ} \mathrm{L}$ \\
\hline 24 & $\# \mathrm{H}$ & $\# \mathrm{H}$ & ${ }^{\circ} \mathrm{L} \#$ & ${ }^{\circ} \mathrm{L}$ \\
\hline 25 & $\# \mathrm{H}$ & $\# \mathrm{H}$ & ${ }^{\circ} \mathrm{L} \#$ & ${ }^{\circ} \mathrm{L}$ \\
\hline 26 & $\mathrm{H} \$$ & HS & $\mathrm{H} \#$ & $\mathrm{H} \$$ \\
\hline 27 & $\# \mathrm{H}$ & $\# \mathrm{H}$ & MH\# & MH\# \\
\hline 28 & $\mathrm{H} \$$ & $\mathrm{H} \$$ & $\mathrm{H} \#$ & H\$ \\
\hline 29 & $\# \mathrm{H}$ & $\# \mathrm{H}$ & ${ }^{\circ} \mathrm{L} \#$ & ${ }^{\circ} \mathrm{L}$ \\
\hline 30 & $\# \mathrm{H}$ & $\# \mathrm{H}$ & MH\# & MH\# \\
\hline 31 & $\mathrm{H} \$$ & H\$ & MH\# & MH\# \\
\hline 32 & $\mathrm{H} \$$ & $\# \mathrm{H}$ & MH\# & MH\# \\
\hline 33 & ${ }^{\circ} \mathrm{L}$ & ${ }^{\circ} \mathrm{L}$ & ${ }^{\circ} \mathrm{L}$ & ${ }^{\circ} \mathrm{L}$ \\
\hline 34 & $\# \mathrm{H}$ & $\# \mathrm{H}$ & ${ }^{\circ} \mathrm{L} \#$ & ${ }^{\circ} \mathrm{L}$ \\
\hline 35 & $\# \mathrm{H}$ & $\# \mathrm{H}$ & ${ }^{\circ} \mathrm{L \#}$ & ${ }^{\circ} \mathrm{L}$ \\
\hline
\end{tabular}




\begin{tabular}{|c|c|c|c|c|}
\hline 36 & $\mathrm{H} \$$ & $\mathrm{H} \$$ & $\mathrm{H \#}$ & $\mathrm{H} \$$ \\
\hline 37 & $\# \mathrm{H}$ & $\# \mathrm{H}$ & MH\# & MH\# \\
\hline 38 & H\$ & $\mathrm{H} \$$ & $\mathrm{H} \#$ & $\mathrm{H} \$$ \\
\hline 39 & $\# \mathrm{H} /{ }^{\circ} \mathrm{L}$ & $\# \mathrm{H}$ & ${ }^{\circ} \mathrm{L} \#$ & ${ }^{\circ} \mathrm{L}$ \\
\hline 40 & L\# & $\mathrm{L \#}^{\circ}$ & $\mathrm{L} \#^{\circ}$ & $\mathrm{L} \#^{\circ}$ \\
\hline 41 & $\mathrm{~L} \#^{\circ} \mathrm{H} \$$ / L\#० & $\mathrm{L}^{\circ} \mathrm{H} \$ / \mathrm{L} \#^{\circ}$ & $\mathrm{L}^{\circ} \mathrm{MH} \# / \mathrm{L} \#^{\circ}$ & $\mathrm{L} \#^{\circ} \mathrm{MH} \#$ \\
\hline 42 & $\mathrm{~L} \#^{\circ} \mathrm{H} \$$ / L\#० & $\mathrm{L} \#^{\circ} \# \mathrm{H} / \mathrm{L} \#^{\circ}$ & $\mathrm{L} \#^{\circ} \mathrm{MH} \# / \mathrm{L} \#^{\circ}$ & L\#OH\# \\
\hline 43 & $\mathrm{~L} \#^{\circ} \mathrm{L}$ & $\mathrm{L} \#^{\circ} \mathrm{L} / \mathrm{L} \#^{\circ}$ & $\mathrm{L} \#^{\circ} \mathrm{L}$ & $\mathrm{L} \#^{\circ} \mathrm{L}$ \\
\hline 44 & $\mathrm{~L} \#^{\circ} \# \mathrm{H} / \mathrm{L} \#^{\circ}$ & 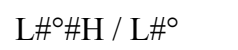 & $\mathrm{L}^{\circ} \mathrm{L} \#$ & $\mathrm{~L}^{\circ} \mathrm{L}$ \\
\hline 45 & $\mathrm{~L} \#^{\circ} \# \mathrm{H} / \mathrm{L} \#^{\circ}$ & $\mathrm{L} \#^{\circ} \# \mathrm{H} / \mathrm{L} \#^{\circ}$ & $\mathrm{L} \#^{\circ} \mathrm{L} \#$ & $\mathrm{~L}^{\circ} \mathrm{L}$ \\
\hline 46 & $\mathrm{~L} \#^{\circ} \mathrm{H} \$$ & $\mathrm{~L} \#^{\circ} \mathrm{H} \$$ & $\mathrm{~L} \#^{\circ} \mathrm{H} \#$ & $\mathrm{~L} \#^{\circ} \mathrm{H} \$$ \\
\hline 47 & $\mathrm{~L} \#^{\circ} \# \mathrm{H}$ & $\mathrm{L} \#^{\circ} \# \mathrm{H}$ & $\mathrm{L} \#^{\circ} \mathrm{MH} \#$ & $\mathrm{~L} \#^{\circ} \mathrm{MH} \#$ \\
\hline 48 & $\mathrm{~L} \#^{\circ} \mathrm{H} \$$ & $\mathrm{~L} \#^{\circ} \mathrm{H} \$$ & $\mathrm{~L} \#{ }^{\circ} \mathrm{H} \#$ & $\mathrm{~L} \#^{\circ} \mathrm{H} \$$ \\
\hline 49 & $\mathrm{~L} \#^{\circ} \# \mathrm{H} / \mathrm{L} \#^{\circ} \mathrm{L}$ & $\mathrm{L} \#^{\circ} \# \mathrm{H} / \mathrm{L} \#^{\circ}$ & $\mathrm{L} \#^{\circ} \mathrm{L} \#$ & $\mathrm{~L} \#^{\circ} \mathrm{L}$ \\
\hline 50 & $\mathrm{~L} \#^{\circ}$ & $\mathrm{L} \#^{\circ}$ & $\mathrm{L \#}^{\circ}$ & $\mathrm{L} \#^{\circ}$ \\
\hline 51 & $\mathrm{~L} \#^{\circ} \mathrm{H} \$$ / L\#० & $\mathrm{L} \#^{\circ} \mathrm{H} \$ / \mathrm{L} \#^{\circ}$ & $\mathrm{L} \#^{\circ} \mathrm{MH} / \mathrm{L} \#^{\circ}$ & $\mathrm{L} \#^{\circ} \mathrm{MH} \#$ \\
\hline 52 & $\mathrm{~L} \#^{\circ} \mathrm{H} \$ / \mathrm{L} \#^{\circ}$ & 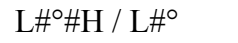 & $\mathrm{L} \#^{\circ} \mathrm{MH} / \mathrm{L} \#^{\circ}$ & $\mathrm{L} \#^{\circ} \mathrm{MH} \#$ \\
\hline 53 & $\mathrm{~L} \#^{\circ}$ & $\mathrm{L \#}^{\circ}$ & $\mathrm{L} \#^{\circ} \mathrm{L}$ & $\mathrm{L} \#^{\circ} \mathrm{L}$ \\
\hline 54 & $\mathrm{~L} \#^{\circ} \# \mathrm{H} / \mathrm{L} \#^{\circ}$ & 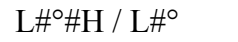 & $\mathrm{L} \#{ }^{\circ} \mathrm{L} \#$ & $\mathrm{~L}^{\circ} \mathrm{L}$ \\
\hline 55 & $\mathrm{~L} \#^{\circ} \# \mathrm{H} / \mathrm{L} \#^{\circ}$ & $\mathrm{L} \#^{\circ} \# \mathrm{H} / \mathrm{L} \#^{\circ}$ & $\mathrm{L}^{\circ} \mathrm{L} \#$ & $\mathrm{~L} \#^{\circ} \mathrm{L}$ \\
\hline 56 & $\mathrm{~L} \#^{\circ} \mathrm{H} \$$ & $\mathrm{~L} \#^{\circ} \mathrm{H} \$$ & $\mathrm{~L} \#{ }^{\circ} \mathrm{H} \#$ & $\mathrm{~L} \#^{\circ} \mathrm{H} \$$ \\
\hline 57 & $\mathrm{~L} \#^{\circ} \# \mathrm{H}$ & $\mathrm{L} \#^{\circ} \# \mathrm{H}$ & $\mathrm{L} \#^{\circ} \mathrm{MH} \#$ & L\#०MH\# \\
\hline 58 & $\mathrm{~L} \#^{\circ} \mathrm{H} \$$ & $\mathrm{~L} \#^{\circ} \mathrm{H} \$$ & $\mathrm{~L} \#^{\circ} \mathrm{H} \#$ & L\# $\mathrm{H} \$$ \\
\hline 59 & $\mathrm{~L} \#^{\circ} \# \mathrm{H} / \mathrm{L} \#^{\circ}$ & $\mathrm{L} \#^{\circ} \# \mathrm{H} / \mathrm{L} \#^{\circ}$ & $\mathrm{L} \#{ }^{\circ} \mathrm{L} \#$ & $\mathrm{~L} \#^{\circ} \mathrm{L}$ \\
\hline 60 & $\mathrm{LM}^{\circ} \mathrm{H} \$$ & $\mathrm{LM}^{\circ} \mathrm{H} \$$ & $\mathrm{LM}^{\circ} \mathrm{H} \#$ & $\mathrm{LM}^{\circ} \# \mathrm{H}$ \\
\hline 61 & $\mathrm{LM}^{\circ} \mathrm{H} \$$ & $\mathrm{LM}^{\circ} \mathrm{HS}$ & $\mathrm{LM}^{\circ} \mathrm{H} \#$ & $\mathrm{LM}^{\circ} \# \mathrm{H}$ \\
\hline 62 & $\begin{array}{l}\mathrm{LM}^{\circ} \mathrm{H} \$ / \\
\mathrm{LM}^{\circ} \# \mathrm{H}\end{array}$ & $\mathrm{LM}^{\circ} \# \mathrm{H}$ & $\mathrm{LM}^{\circ} \mathrm{H} \#$ & $\mathrm{LM}^{\circ} \mathrm{H} \#$ \\
\hline 63 & $\mathrm{LM}^{\circ} \mathrm{H} \$ / \mathrm{LM}^{\circ} \mathrm{L}$ & $\mathrm{LM}^{\circ} \mathrm{H} \$ / \mathrm{LM}^{\circ} \mathrm{L}$ & $\mathrm{LM}^{\circ} \mathrm{H} \#$ & $\mathrm{LM}^{\circ} \mathrm{H} \#$ \\
\hline 64 & $\mathrm{LM}^{\circ} \# \mathrm{H}$ & $\mathrm{LM}^{\circ} \# \mathrm{H}$ & $\mathrm{LM}^{\circ} \mathrm{H} \#$ & $\mathrm{LM}^{\circ} \mathrm{H} \#$ \\
\hline 65 & $\mathrm{LM}^{\circ} \# \mathrm{H}$ & $\mathrm{LM}^{\circ} \# \mathrm{H}$ & $\mathrm{LM}^{\circ} \mathrm{H} \#$ & $\mathrm{LM}^{\circ} \mathrm{H} \#$ \\
\hline 66 & $\mathrm{LM}^{\circ} \mathrm{H} \$$ & $\mathrm{LM}^{\circ} \mathrm{H} \$$ & $\mathrm{LM}^{\circ} \mathrm{H} \#$ & $\mathrm{LM}^{\circ} \mathrm{H} \#$ \\
\hline 67 & $\mathrm{LM}^{\circ} \# \mathrm{H}$ & $\mathrm{LM}^{\circ} \# \mathrm{H}$ & $\mathrm{LM}^{\circ} \mathrm{H} \#$ & $\mathrm{LM}^{\circ} \mathrm{H} \#$ \\
\hline 68 & $\mathrm{LM}^{\circ} \mathrm{H} \$$ & $\mathrm{LM}^{\circ} \mathrm{H} \$$ & $\mathrm{LM}^{\circ} \mathrm{H} \#$ & $\mathrm{LM}^{\circ} \mathrm{H} \#$ \\
\hline 69 & $\mathrm{LM}^{\circ} \# \mathrm{H} / \mathrm{LM}^{\circ} \mathrm{L}$ & $\mathrm{LM}^{\circ} \mathrm{L}$ & $\mathrm{LM}^{\circ} \mathrm{H} \#$ & $\mathrm{LM}^{\circ} \mathrm{H} \#$ \\
\hline 70 & $\mathrm{~L} \#^{\circ}$ & $\mathrm{L} \#^{\circ}$ & $\mathrm{L}^{\circ}$ & $\mathrm{L}^{\circ}$ \\
\hline 71 & $\mathrm{~L} \#^{\circ} \mathrm{H} \$$ / L\#० & $\mathrm{L} \#{ }^{\circ} \mathrm{H} \$$ & $\mathrm{~L} \#^{\circ} \mathrm{MH} \# / \mathrm{L} \#^{\circ}$ & L\#०MH\# \\
\hline 72 & $\mathrm{~L} \#^{\circ} \mathrm{H} \$ / \mathrm{L} \#^{\circ}$ & $\mathrm{L} \#{ }^{\circ} \# \mathrm{H}$ & L\# ${ }^{\circ} \mathrm{MH} \# /$ L\# & L\# ${ }^{\circ} H \#$ \\
\hline 73 & $\mathrm{~L}^{\circ} \mathrm{L}$ & $\mathrm{L} \#^{\circ} \mathrm{L}$ & $\mathrm{L} \#^{\circ} \mathrm{L}$ & $\mathrm{L} \#{ }^{\circ} \mathrm{L}$ \\
\hline
\end{tabular}




\begin{tabular}{|c|c|c|c|c|c|}
\hline 74 & $\mathrm{~L} \#^{\circ} \# \mathrm{H}$ & & $\mathrm{L}^{\circ} \mathrm{HH}^{\mathrm{H}}$ & $\mathrm{L}^{\circ} \mathrm{MH} \# / \mathrm{L}^{\circ}$ & $\mathrm{L} \#^{\circ} \mathrm{L}$ \\
\hline 75 & $\mathrm{~L} \#^{\circ} \# \mathrm{H}$ & & $\mathrm{L}^{\circ} \# \mathrm{H}$ & $\mathrm{L}^{\circ} \mathrm{MH} \# / \mathrm{L}^{\circ}$ & $\mathrm{L} \#^{\circ} \mathrm{L}$ \\
\hline 76 & $\mathrm{~L} \#^{\circ} \mathrm{H} \$$ & & $\mathrm{~L} \#^{\circ} \mathrm{H} \$$ & $\mathrm{~L}^{\circ} \mathrm{H} \# / \mathrm{L}^{\circ}$ & $\mathrm{L} \#{ }^{\circ} \mathrm{H} \#$ \\
\hline 77 & $\mathrm{~L} \#^{\circ} \# \mathrm{H}$ & & $\mathrm{L} \#^{\circ} \# \mathrm{H}$ & $\mathrm{L}^{\circ} \mathrm{MH} \# / \mathrm{L}^{\circ}$ & $\mathrm{L} \#^{\circ} \mathrm{MH} \#$ \\
\hline 78 & $\mathrm{~L} \#^{\circ} \mathrm{H} \$$ & & $\mathrm{~L}^{\circ} \mathrm{H} \$$ & $\mathrm{~L}^{\circ} \mathrm{H} \# / \mathrm{L}^{\circ}$ & $\mathrm{L} \#{ }^{\circ} \mathrm{H} \#$ \\
\hline 79 & $\mathrm{~L} \#^{\circ} \# \mathrm{H} / \mathrm{L} \#^{\circ} \mathrm{L}$ & & $\mathrm{L}^{\circ} \# \mathrm{H}$ & $\mathrm{L} \#^{\circ} \mathrm{L} \#$ & $\mathrm{~L}^{\circ} \mathrm{L}$ \\
\hline 80 & $\mathrm{LM}^{\circ} \mathrm{H} \$$ & & $\mathrm{LM}^{\circ} \mathrm{H} \$$ & $\mathrm{LM}^{\circ} \mathrm{H} \#$ & $\mathrm{LM}^{\circ} \mathrm{H} \#$ \\
\hline 81 & $\mathrm{LM}^{\circ} \mathrm{H} \$$ & & $\mathrm{LM}^{\circ} \mathrm{H} \$$ & $\mathrm{LM}^{\circ} \mathrm{H} \#$ & $\mathrm{LM}^{\circ} \mathrm{H} \#$ \\
\hline 82 & $\mathrm{LM}^{\circ} \mathrm{H} \$$ & & $\mathrm{LM}^{\circ} \# \mathrm{H}$ & $\mathrm{LM}^{\circ} \mathrm{H} \#$ & $\mathrm{LM}^{\circ} \mathrm{H} \#$ \\
\hline 83 & $\mathrm{LM}^{\circ} \mathrm{H} \$$ & & $\mathrm{LM}^{\circ} \mathrm{H} \$ / \mathrm{LM}^{\circ} \mathrm{L}$ & $\mathrm{LM}^{\circ} \mathrm{H} \#$ & $\mathrm{LM}^{\circ} \mathrm{H} \#$ \\
\hline 84 & $\mathrm{LM}^{\circ} \# \mathrm{H}$ & & $\mathrm{LM}^{\circ} \mathrm{H} \$$ & $\mathrm{LM}^{\circ} \mathrm{H} \#$ & $\mathrm{LM}^{\circ} \mathrm{H} \#$ \\
\hline 85 & $\mathrm{LM}^{\circ} \# \mathrm{H}$ & & $\mathrm{LM}^{\circ} \# \mathrm{H}$ & $\mathrm{LM}^{\circ} \mathrm{H} \#$ & $\mathrm{LM}^{\circ} \mathrm{H} \#$ \\
\hline 86 & $\mathrm{LM}^{\circ} \mathrm{H} \$$ & & $\mathrm{LM}^{\circ} \mathrm{H} \$$ & $\mathrm{LM}^{\circ} \mathrm{H} \#$ & $\mathrm{LM}^{\circ} \mathrm{H} \#$ \\
\hline 87 & $\mathrm{LM}^{\circ} \# \mathrm{H}$ & & $\mathrm{LM}^{\circ} \# \mathrm{H}$ & $\mathrm{LM}^{\circ} \mathrm{H} \#$ & $\mathrm{LM}^{\circ} \mathrm{H} \#$ \\
\hline 88 & $\mathrm{LM}^{\circ} \mathrm{H} \$$ & & $\mathrm{LM}^{\circ} \mathrm{H} \$$ & $\mathrm{LM}^{\circ} \mathrm{H} \#$ & $\mathrm{LM}^{\circ} \mathrm{H} \#$ \\
\hline 89 & $\mathrm{LM}^{\circ} \# \mathrm{H}$ & & $\mathrm{LM}^{\circ} \# \mathrm{H}$ & $\mathrm{LM}^{\circ} \mathrm{H} \#$ & $\mathrm{LM}^{\circ} \mathrm{H} \#$ \\
\hline 90 & $\mathrm{L \#}^{\circ}$ & & $\mathrm{L} \#^{\circ}$ & $\mathrm{L} \#^{\circ}$ & $\mathrm{L} \#^{\circ}$ \\
\hline 91 & $\mathrm{~L} \#^{\circ} \mathrm{H} \$$ & & $\mathrm{~L} \#^{\circ} \mathrm{H} \$$ & $\mathrm{~L}^{\circ} \mathrm{MH} \# / \mathrm{L} \#^{\circ}$ & $\mathrm{L}^{\circ} \mathrm{MH} \# / \mathrm{L}^{\circ}$ \\
\hline 92 & $\mathrm{~L} \#^{\circ} \mathrm{H} \$$ & & $\mathrm{~L} \#^{\circ} \# \mathrm{H}$ & $\mathrm{L}^{\circ} \mathrm{MH} \# / \mathrm{L}^{\circ}$ & $\mathrm{L} \#^{\circ} \mathrm{MH} \# / \mathrm{L}^{\circ}$ \\
\hline 93 & $\mathrm{~L} \#^{\circ} \mathrm{L}$ & & $\mathrm{L}^{\circ} \mathrm{L}$ & $\mathrm{L}^{\circ} \mathrm{L}$ & $\mathrm{L}^{\circ} \mathrm{L}$ \\
\hline 94 & $\mathrm{~L} \#^{\circ} \# \mathrm{H}$ & & $\mathrm{L} \#^{\circ} \# \mathrm{H}$ & $\mathrm{L}^{\circ} \mathrm{L} \# / \mathrm{L \#}^{\circ}$ & $\mathrm{L} \#^{\circ} \mathrm{L}$ \\
\hline 95 & $\mathrm{~L} \#^{\circ} \# \mathrm{H}$ & & $\mathrm{L}^{\circ}{ }^{\circ} \mathrm{H}$ & $\mathrm{L}^{\circ} \mathrm{L} \# /$ L\# & $\mathrm{L} \#^{\circ} \mathrm{L}$ \\
\hline 96 & $\mathrm{~L} \#^{\circ} \mathrm{H} \$$ & & $\mathrm{~L} \#{ }^{\circ} \mathrm{H} \$$ & $\mathrm{~L}^{\circ} \mathrm{H} \# /$ L\# & $\mathrm{L}^{\circ} \mathrm{H} \# / \mathrm{L} \#^{\circ}$ \\
\hline 97 & $\mathrm{~L} \#^{\circ} \# \mathrm{H}$ & & $\mathrm{L}^{\circ} \# \mathrm{H}$ & $\mathrm{L}^{\circ} \mathrm{MH} \# / \mathrm{L}^{\circ}$ & $\mathrm{L} \#^{\circ} \mathrm{MH} \# / \mathrm{L}^{\circ}$ \\
\hline 98 & $\mathrm{~L} \#^{\circ} \mathrm{H} \$$ & & $\mathrm{~L} \#^{\circ} \mathrm{H} \$$ & $\mathrm{~L}^{\circ} \mathrm{H} \# / \mathrm{L}^{\circ}$ & $\mathrm{L} \#^{\circ} \mathrm{H} \# / \mathrm{L}^{\circ}$ \\
\hline 99 & $\mathrm{~L}^{\circ} \mathrm{L}$ & & $\mathrm{L}^{\circ} \# \mathrm{H}$ & $\mathrm{L} \#^{\circ} \mathrm{L} \# /$ L\# & $\mathrm{L} \#^{\circ} \mathrm{L}$ \\
\hline 100 & $\# \mathrm{H}$ & & $\# \mathrm{H}$ & $\mathrm{MH \#}$ & MH\# \\
\hline \multicolumn{6}{|c|}{ Part 2: $\mathrm{M}$ and $\mathrm{L}$ tones. } \\
\hline & M1 & M2 & L1 & L2 & L3 \\
\hline 1 & $\mathrm{M}$ & $\mathrm{M}$ & L\# & L\# & L\# \\
\hline 2 & M & M & L\# & L\# & L\# \\
\hline 3 & M & M & $\mathrm{L}$ & $\mathrm{M}$ & $\mathrm{M}$ \\
\hline 4 & $\mathrm{~L}$ & $\mathrm{~L}$ & $\mathrm{H \#}$ & $\mathrm{H} \#$ & $\mathrm{H} \#$ \\
\hline 5 & $\mathrm{~L}$ & $\mathrm{~L}$ & $\mathrm{H \#}$ & $\mathrm{H \#}$ & $\mathrm{H \#}$ \\
\hline 6 & $\mathrm{H} \#$ & H\$ & $\mathrm{H} \#$ & $\mathrm{H} \#$ & $\mathrm{H} \#$ \\
\hline 7 & M & M & L\# & L\# & L\# \\
\hline 8 & $\mathrm{H \#}$ & $\mathrm{H} \$$ & $\mathrm{H} \#$ & $\mathrm{H \#}$ & $\mathrm{H \#}$ \\
\hline 9 & $\mathrm{~L}$ & $\mathrm{~L}$ & $\mathrm{H} \#$ & $\mathrm{H \#} \mathrm{/} \mathrm{L \#}$ & $\mathrm{H} \#$ \\
\hline 10 & M & M & $\mathrm{L}$ & $\mathrm{M}$ & $\mathrm{L}$ \\
\hline
\end{tabular}




\begin{tabular}{|c|c|c|c|c|c|}
\hline 11 & M & M & L\# & L\# & L\# \\
\hline 12 & M & M & L\# & L\# & L\# \\
\hline 13 & M & M & L\# & L\# & L\# \\
\hline 14 & $\mathrm{~L}+\mathrm{H} \#$ & $\mathrm{~L}$ & $\mathrm{~L}+\mathrm{H} \#$ & $\mathrm{~L}+\mathrm{H} \#$ & $\mathrm{~L}+\mathrm{H} \#$ \\
\hline 15 & $\mathrm{~L}+\mathrm{H} \#$ & $\mathrm{~L}$ & $\mathrm{~L}+\mathrm{H} \#$ & $\mathrm{~L}+\mathrm{H} \#$ & $\mathrm{~L}+\mathrm{H} \#$ \\
\hline 16 & $\mathrm{~L}+\mathrm{H} \#$ & $\mathrm{~L}$ & $\mathrm{~L}+\mathrm{H} \#$ & $\mathrm{~L}+\mathrm{H} \#$ & $\mathrm{~L}+\mathrm{H} \#$ \\
\hline 17 & M & M & L\# & L\# & L\# \\
\hline 18 & $\mathrm{~L}+\mathrm{H} \#$ & $\mathrm{~L}$ & $\mathrm{~L}+\mathrm{H} \#$ & $\mathrm{~L}+\mathrm{H} \#$ & $\mathrm{~L}+\mathrm{H} \#$ \\
\hline 19 & $\mathrm{~L}+\mathrm{H} \#$ & $\mathrm{~L}$ & $\mathrm{~L}+\mathrm{H} \#$ & $\mathrm{~L}+\mathrm{H} \#$ & $\mathrm{~L}+\mathrm{H} \#$ \\
\hline 20 & M & M & ${ }^{\circ} \mathrm{L}$ & ${ }^{\circ} \mathrm{L}$ & ${ }^{\circ} \mathrm{L}$ \\
\hline 21 & M & $\mathrm{M}$ & ${ }^{\circ} \mathrm{L} \#$ & ${ }^{\circ} \mathrm{L} \#$ & ${ }^{\circ} \mathrm{L} \#$ \\
\hline 22 & M & M & ${ }^{\circ} \mathrm{L} \#$ & ${ }^{\circ} \mathrm{L} \#$ & ${ }^{\circ} \mathrm{L} \#$ \\
\hline 23 & ${ }^{\circ} \mathrm{L} / \mathrm{M}$ & $\mathrm{M} /{ }^{\circ} \mathrm{L}$ & ${ }^{\circ} \mathrm{L}$ & ${ }^{\circ} \mathrm{L}$ & ${ }^{\circ} \mathrm{L}$ \\
\hline 24 & ${ }^{\circ} \mathrm{L}$ & ${ }^{\circ} \mathrm{L}$ & $\mathrm{H} \#$ & $\mathrm{H} \#$ & $\mathrm{H} \#$ \\
\hline 25 & ${ }^{\circ} \mathrm{L}$ & ${ }^{\circ} \mathrm{L}$ & $\mathrm{H} \#$ & $\mathrm{H} \#$ & $\mathrm{H} \#$ \\
\hline 26 & $\mathrm{H \#}$ & HS & $\mathrm{H} \#$ & $\mathrm{H} \#$ & $\mathrm{H} \#$ \\
\hline 27 & M & M & ${ }^{\circ} \mathrm{L} \#$ & ${ }^{\circ} \mathrm{L} \#$ & ${ }^{\circ} \mathrm{L} \#$ \\
\hline 28 & $\mathrm{H \#}$ & $\mathrm{H} \$$ & $\mathrm{H} \#$ & $\mathrm{H} \#$ & $\mathrm{H} \#$ \\
\hline 29 & ${ }^{\circ} \mathrm{L}$ & ${ }^{\circ} \mathrm{L}$ & $\mathrm{H} \#$ & ${ }^{\circ} \mathrm{L} \# / \mathrm{H} \#$ & $\mathrm{H} \#$ \\
\hline 30 & M & M & ${ }^{\circ} \mathrm{L} \#$ & ${ }^{\circ} \mathrm{L}$ & ${ }^{\circ} \mathrm{L} \#$ \\
\hline 31 & M & M & ${ }^{\circ} \mathrm{L} \#$ & ${ }^{\circ} \mathrm{L} \#$ & ${ }^{\circ} \mathrm{L} \#$ \\
\hline 32 & M & M & ${ }^{\circ} \mathrm{L} \#$ & ${ }^{\circ} \mathrm{L} \#$ & ${ }^{\circ} \mathrm{L} \#$ \\
\hline 33 & ${ }^{\circ} \mathrm{L}$ & ${ }^{\circ} \mathrm{L}$ & ${ }^{\circ} \mathrm{L}$ & ${ }^{\circ} \mathrm{L}$ & ${ }^{\circ} \mathrm{L}$ \\
\hline 34 & ${ }^{\circ} \mathrm{L}$ & ${ }^{\circ} \mathrm{L}$ & $\mathrm{H} \#$ & $\mathrm{H} \#$ & $\mathrm{H} \#$ \\
\hline 35 & ${ }^{\circ} \mathrm{L}$ & ${ }^{\circ} \mathrm{L}$ & $\mathrm{H \#}$ & $\mathrm{H} \#$ & $\mathrm{H} \#$ \\
\hline 36 & $\mathrm{H \#}$ & $\mathrm{H} \$$ & $\mathrm{H} \#$ & $\mathrm{H} \#$ & $\mathrm{H \#}$ \\
\hline 37 & M & $\mathrm{L}$ & ${ }^{\circ} \mathrm{L} \#$ & ${ }^{\circ} \mathrm{L} \#$ & ${ }^{\circ} \mathrm{L} \#$ \\
\hline 38 & $\mathrm{H} \#$ & $\mathrm{HS}$ & $\mathrm{H} \#$ & $\mathrm{H} \#$ & $\mathrm{H} \#$ \\
\hline 39 & ${ }^{\circ} \mathrm{L}$ & ${ }^{\circ} \mathrm{L}$ & $\mathrm{H} \# /{ }^{\circ} \mathrm{L} \#$ & $\mathrm{H} \# /{ }^{\circ} \mathrm{L} \#$ & $\mathrm{H} \# /{ }^{\circ} \mathrm{L} \#$ \\
\hline 40 & $\mathrm{~L}^{\circ}$ & $\mathrm{L} \#^{\circ}$ & $\mathrm{L \#}^{\circ}$ & $\mathrm{L}^{\circ}$ & $\mathrm{L} \#^{\circ}$ \\
\hline 41 & $\mathrm{~L}^{\circ}$ & $\mathrm{L} \#^{\circ} \mathrm{M} / \mathrm{L} \#^{\circ}$ & $\mathrm{L} \#^{\circ} \mathrm{L} \# /$ L\# & $\mathrm{L} \#^{\circ} \mathrm{L} \# /$ L\# & $\mathrm{L} \#^{\circ} \mathrm{L \#} / \mathrm{L} \#^{\circ}$ \\
\hline 42 & $\mathrm{~L}^{\circ}$ & $\mathrm{L}^{\circ} \mathrm{M} / \mathrm{L} \#^{\circ}$ & $\mathrm{L}^{\circ} \mathrm{L} \# /$ L\# & $\mathrm{L} \#^{\circ} \mathrm{L} \# /$ L\# & $\mathrm{L}^{\circ} \mathrm{L} \# / \mathrm{L}^{\circ}$ \\
\hline 43 & $\mathrm{~L} \#^{\circ}$ & $\mathrm{L} \#^{\circ} \mathrm{M} / \mathrm{L} \#^{\circ}$ & $\mathrm{L} \#^{\circ} \mathrm{M} / \mathrm{L} \#^{\circ} \mathrm{L}$ & $\mathrm{L} \#^{\circ} \mathrm{M} / \mathrm{L} \#^{\circ}$ & $\mathrm{L}^{\circ} \mathrm{M} / \mathrm{L} \#^{\circ}$ \\
\hline 44 & $\mathrm{~L} \#^{\circ} \mathrm{H} \# /$ L\# & $\mathrm{L} \#^{\circ}$ & $\mathrm{L} \#^{\circ} \mathrm{H \#} / \mathrm{L} \#^{\circ}$ & $\mathrm{L} \#^{\circ} \mathrm{H} \# /$ L\# & $\mathrm{L} \#^{\circ} \mathrm{H} \# /$ L\# \\
\hline 45 & $\mathrm{~L} \#^{\circ} \mathrm{H} \# /$ L\# & $\mathrm{L}^{\circ}$ & $\mathrm{L} \#^{\circ} \mathrm{H \#} / \mathrm{L} \#^{\circ}$ & $\mathrm{L} \#^{\circ} \mathrm{H} \# /$ L\# & $\mathrm{L} \#^{\circ} \mathrm{H} \# /$ L\# \\
\hline 46 & $\mathrm{~L} \#^{\circ} \mathrm{H} \# /$ L\# & $\mathrm{L} \#^{\circ} \mathrm{H} \$ / \mathrm{L} \#^{\circ}$ & $\mathrm{L}^{\circ} \mathrm{H \#} / \mathrm{L} \#^{\circ}$ & $\mathrm{L} \#^{\circ} \mathrm{H} \# /$ L\# & $\mathrm{L} \#^{\circ} \mathrm{H} \# /$ L\# \\
\hline 47 & $\mathrm{~L} \#^{\circ} \mathrm{M} / \mathrm{L} \#^{\circ}$ & $\mathrm{L} \#^{\circ} \mathrm{M} / \mathrm{L} \#^{\circ}$ & $\mathrm{L} \#^{\circ} \mathrm{L} \# /$ L\# & $\mathrm{L} \#^{\circ} \mathrm{L} \# /$ L\# & $\mathrm{L} \#^{\circ} \mathrm{L} \# /$ L\# \\
\hline 48 & $\mathrm{~L} \#^{\circ} \mathrm{H} \# /$ L\# & $\mathrm{L} \#^{\circ} \mathrm{H} \$ / \mathrm{L} \#^{\circ}$ & $\mathrm{L} \#^{\circ} \mathrm{H} \# /$ L\# & $\mathrm{L} \#^{\circ} \mathrm{H} \# /$ L\# & $\mathrm{L} \#^{\circ} \mathrm{H} \# / \mathrm{L} \#^{\circ}$ \\
\hline 49 & $\mathrm{~L}{ }^{\circ} \mathrm{H} \# /$ L\# & $\mathrm{L} \#{ }^{\circ} \mathrm{L}$ & $\mathrm{L} \#{ }^{\circ} \mathrm{H} \# /$ L\# & $\mathrm{L} \#^{\circ} \mathrm{H} \# /$ L\# & $\mathrm{L} \#^{\circ} \mathrm{H} \# / / \mathrm{L} \#^{\circ}$ \\
\hline
\end{tabular}




\begin{tabular}{|c|c|c|c|c|c|}
\hline 50 & $\mathrm{L \#}^{\circ}$ & $\mathrm{L} \#^{\circ}$ & $\mathrm{L \#}^{\circ}$ & $\mathrm{L \#}^{\circ}$ & $\mathrm{L \#}^{\circ}$ \\
\hline 51 & $\mathrm{~L}^{\circ}$ & $\mathrm{L} \#^{\circ} \mathrm{M} / \mathrm{L} \#^{\circ}$ & $\mathrm{L}^{\circ} \mathrm{L} \# / \mathrm{L \#}^{\circ}$ & $\mathrm{L} \#^{\circ} \mathrm{L} \# / \mathrm{L}^{\circ}$ & $\mathrm{L} \#^{\circ} \mathrm{L} \# / \mathrm{L}^{\circ}$ \\
\hline 52 & $\mathrm{~L} \#^{\circ}$ & $\mathrm{L} \#^{\circ} \mathrm{M} / \mathrm{L} \#^{\circ}$ & $\mathrm{L}^{\circ} \mathrm{L} \# / \mathrm{L}^{\circ}$ & $\mathrm{L}^{\circ} \mathrm{L} \# / \mathrm{L \#}^{\circ}$ & $\mathrm{L} \#^{\circ} \mathrm{L} \# / \mathrm{LH}^{\circ}$ \\
\hline 53 & $\mathrm{~L} \#^{\circ}$ & $\mathrm{L} \#^{\circ} \mathrm{M} / \mathrm{L} \#^{\circ}$ & $\mathrm{L} \#^{\circ} \mathrm{M} / \mathrm{L} \#^{\circ} \mathrm{L}$ & $\mathrm{L} \#^{\circ} \mathrm{M} / \mathrm{L} \#^{\circ}$ & $\mathrm{L} \#^{\circ} \mathrm{M} / \mathrm{L} \#^{\circ}$ \\
\hline 54 & $\mathrm{~L} \#^{\circ} \mathrm{H} \# /$ L\# ${ }^{\circ}$ & $\mathrm{L} \#^{\circ}$ & $\mathrm{L} \#^{\circ} \mathrm{H} \# / \mathrm{L}^{\circ}$ & $\mathrm{L} \#^{\circ} \mathrm{H} \# / \mathrm{L}^{\circ}$ & $\mathrm{L} \#^{\circ} \mathrm{H} \# /$ L\# \\
\hline 55 & $\mathrm{~L} \#^{\circ} \mathrm{H} \# / \mathrm{L}^{\circ}$ & $\mathrm{L} \#^{\circ}$ & $\mathrm{L} \#^{\circ} \mathrm{H} \# / \mathrm{L}^{\circ}$ & $\mathrm{L} \#^{\circ} \mathrm{H} \# / \mathrm{L}^{\circ}$ & $\mathrm{L} \#^{\circ} \mathrm{H} \# / \mathrm{L}^{\circ}$ \\
\hline 56 & $\mathrm{~L} \#^{\circ} \mathrm{H} \# / \mathrm{L}^{\circ}$ & $\mathrm{L} \#^{\circ} \mathrm{H} \$ / \mathrm{L}^{\circ}$ & $\mathrm{L} \#^{\circ} \mathrm{H} \# / \mathrm{L}^{\circ}$ & $\mathrm{L} \#^{\circ} \mathrm{H} \# / \mathrm{L}^{\circ}$ & $\mathrm{L} \#^{\circ} \mathrm{H} \# / \mathrm{L}^{\circ}$ \\
\hline 57 & $\mathrm{~L} \#^{\circ} \mathrm{M} / \mathrm{L}^{\circ}$ & $\mathrm{L} \#^{\circ} \mathrm{M} / \mathrm{L} \#^{\circ}$ & $\mathrm{L}^{\circ} \mathrm{L} \# / \mathrm{L}^{\circ}$ & $\mathrm{L}^{\circ} \mathrm{L} \# / \mathrm{L}^{\circ}$ & $\mathrm{L}^{\circ} \mathrm{L} \# / \mathrm{L}^{\circ}$ \\
\hline 58 & $\mathrm{~L} \#^{\circ} \mathrm{H} \#$ / L\# ${ }^{\circ}$ & $\mathrm{L} \#^{\circ} \mathrm{H} \$ / \mathrm{L} \#^{\circ}$ & $\mathrm{L} \#^{\circ} \mathrm{H} \# / \mathrm{L}^{\circ}$ & $\mathrm{L} \#^{\circ} \mathrm{H} \# /$ L\# & $\mathrm{L} \#^{\circ} \mathrm{H} \# /$ L\# \\
\hline 59 & $\mathrm{~L} \#^{\circ} \mathrm{H} \# / \mathrm{L}^{\circ}$ & $\mathrm{L}^{\circ} \mathrm{L}$ & $\mathrm{L} \#^{\circ} \mathrm{H} \# / \mathrm{L}^{\circ}$ & $\mathrm{L} \#^{\circ} \mathrm{H} \# / \mathrm{L}^{\circ}$ & $\mathrm{L} \#^{\circ} \mathrm{H} \# /$ L\# \\
\hline 60 & $\mathrm{LM}^{\circ} \mathrm{H} \#$ & $\mathrm{LM}^{\circ} \mathrm{H} \$$ & $\mathrm{LM}^{\circ} \mathrm{H} \#$ & $\mathrm{LM}^{\circ} \mathrm{H} \#$ & $\mathrm{LM}^{\circ} \mathrm{H} \#$ \\
\hline 61 & $\begin{array}{l}\mathrm{LM}^{\circ} \mathrm{H} \# / \\
\mathrm{L}+\mathrm{MH} \#^{\circ} \mathrm{M}\end{array}$ & $\mathrm{LM}^{\circ} \mathrm{H} \$$ & $\mathrm{LM}^{\circ} \mathrm{H} \#$ & $\mathrm{LM}^{\circ} \mathrm{H} \#$ & $\mathrm{LM}^{\circ} \mathrm{H} \#$ \\
\hline 62 & $\begin{array}{l}\mathrm{LM}^{\circ} \mathrm{H} \# / \\
\mathrm{L}+\mathrm{MH}^{\circ} \mathrm{M}\end{array}$ & $\mathrm{LM}^{\circ} \mathrm{H} \$$ & $\mathrm{LM}^{\circ} \mathrm{H} \#$ & $\mathrm{LM}^{\circ} \mathrm{H} \#$ & $\mathrm{LM}^{\circ} \mathrm{H} \#$ \\
\hline 63 & $\begin{array}{l}\mathrm{LM}^{\circ} \mathrm{H} \# / \\
\mathrm{L}+\mathrm{MH} \#^{\circ} \mathrm{M}\end{array}$ & $\mathrm{LM}^{\circ} \mathrm{H} \$$ & $\mathrm{LM}^{\circ} \mathrm{H} \#$ & $\mathrm{LM}^{\circ} \mathrm{H} \#$ & $\mathrm{LM}^{\circ} \mathrm{H} \#$ \\
\hline 64 & $\begin{array}{l}\mathrm{LM}^{\circ} \mathrm{H} \# / \\
\mathrm{L}+\mathrm{MH}^{\circ} \mathrm{L}\end{array}$ & $\mathrm{LM}^{\circ} \mathrm{H} \$$ & $\mathrm{LM}^{\circ} \mathrm{H} \#$ & $\mathrm{LM}^{\circ} \mathrm{H} \#$ & $\mathrm{LM}^{\circ} \mathrm{H} \#$ \\
\hline 65 & $\begin{array}{l}\mathrm{LM}^{\circ} \mathrm{H} \# / \\
\mathrm{L}+\mathrm{MH}^{\circ} \mathrm{L}\end{array}$ & $\mathrm{LM}^{\circ} \mathrm{H} \$$ & $\mathrm{LM}^{\circ} \mathrm{H} \#$ & $\mathrm{LM}^{\circ} \mathrm{H} \#$ & $\mathrm{LM}^{\circ} \mathrm{H} \#$ \\
\hline 66 & $\mathrm{LM}^{\circ} \mathrm{H} \#$ & $\mathrm{LM}^{\circ} \mathrm{H} \$$ & $\mathrm{LM}^{\circ} \mathrm{H} \#$ & $\mathrm{LM}^{\circ} \mathrm{H} \#$ & $\mathrm{LM}^{\circ} \mathrm{H} \#$ \\
\hline 67 & $\begin{array}{l}\mathrm{LM}^{\circ} \mathrm{H} \# / / \\
\mathrm{L}+\mathrm{MH}^{\circ} \mathrm{M}\end{array}$ & $\mathrm{LM}^{\circ} \# \mathrm{H}$ & $\mathrm{LM}^{\circ} \mathrm{H} \#$ & $\mathrm{LM}^{\circ} \mathrm{H} \#$ & $\mathrm{LM}^{\circ} \mathrm{H} \#$ \\
\hline 68 & $\mathrm{LM}^{\circ} \mathrm{H} \#$ & $\mathrm{LM}^{\circ} \mathrm{H} \$$ & $\mathrm{LM}^{\circ} \mathrm{H} \#$ & $\mathrm{LM}^{\circ} \mathrm{H} \#$ & $\mathrm{LM}^{\circ} \mathrm{H} \#$ \\
\hline 69 & $\begin{array}{l}\mathrm{LM}^{\circ} \mathrm{H} \# / \\
\mathrm{L}+\mathrm{MH}^{\circ} \mathrm{L}\end{array}$ & $\begin{array}{l}\mathrm{LM}^{\circ} \mathrm{H} \$ / \\
\mathrm{LM}^{\circ} \mathrm{L}\end{array}$ & $\mathrm{LM}^{\circ} \mathrm{H} \#$ & $\mathrm{LM}^{\circ} \mathrm{H} \#$ & $\mathrm{LM}^{\circ} \mathrm{H} \#$ \\
\hline 70 & $\mathrm{~L} \#^{\circ}$ & $\mathrm{L} \#^{\circ}$ & $\mathrm{L \#}^{\circ}$ & $\mathrm{L}^{\circ}$ & $\mathrm{L} \#^{\circ}$ \\
\hline 71 & $\mathrm{~L} \#^{\circ} / \mathrm{L}^{\circ} \mathrm{M}$ & $\mathrm{L} \#^{\circ} \mathrm{M} / \mathrm{L} \#^{\circ}$ & $\mathrm{L} \#^{\circ} \mathrm{L} \# / / \#^{\circ}$ & $\mathrm{L} \#^{\circ} \mathrm{L} \# /$ L\# & $\mathrm{L} \#^{\circ} \mathrm{L} \# / \mathrm{L}^{\circ}$ \\
\hline 72 & $\mathrm{~L} \#^{\circ} / \mathrm{L}^{\circ} \mathrm{M}$ & $\mathrm{L} \#^{\circ} \mathrm{M} / \mathrm{L} \#^{\circ}$ & $\mathrm{L}^{\circ} \mathrm{L} \# / \mathrm{L}^{\circ}$ & $\mathrm{L}^{\circ} \mathrm{L} \# / \mathrm{L \#}^{\circ}$ & $\mathrm{L} \#^{\circ} \mathrm{L} \# / \mathrm{L}^{\circ}$ \\
\hline 73 & $\mathrm{~L}^{\circ} / \mathrm{L} \#^{\circ} \mathrm{M}$ & $\mathrm{L} \#^{\circ} \mathrm{M} / \mathrm{L} \#^{\circ}$ & $\mathrm{L}^{\circ} \mathrm{L}$ & $\mathrm{L} \#^{\circ} \mathrm{M} / \mathrm{L} \#^{\circ}$ & $\mathrm{L} \#^{\circ} \mathrm{M} / \mathrm{L} \#^{\circ}$ \\
\hline 74 & $\mathrm{~L}^{\circ} / \mathrm{L} \#^{\circ} \mathrm{H} \#$ & $\mathrm{~L} \#^{\circ} \mathrm{L}$ & $\mathrm{L} \#^{\circ} \mathrm{H} \# / \mathrm{L}^{\circ}$ & $\mathrm{L} \#^{\circ} \mathrm{H} \# / \mathrm{L}^{\circ}$ & $\mathrm{L} \#^{\circ} \mathrm{H} \# / \mathrm{L}^{\circ}$ \\
\hline 75 & $\mathrm{~L} \#^{\circ} / \mathrm{L} \#^{\circ} \mathrm{H} \#$ & $\mathrm{~L} \#^{\circ} \mathrm{L}$ & $\mathrm{L} \#^{\circ} \mathrm{H} \# / \mathrm{L}^{\circ}$ & $\mathrm{L} \#^{\circ} \mathrm{H} \# / \mathrm{L}^{\circ}$ & $\mathrm{L} \#^{\circ} \mathrm{H} \# / \mathrm{L}^{\circ}$ \\
\hline 76 & $\mathrm{~L} \#^{\circ} \mathrm{H} \# / \mathrm{L}^{\circ}$ & $\mathrm{L} \#^{\circ} \mathrm{H} \$ / \mathrm{L}^{\circ}$ & $\mathrm{L} \#^{\circ} \mathrm{H} \# / \mathrm{L}^{\circ}$ & $\mathrm{L} \#^{\circ} \mathrm{H} \# / \mathrm{L}^{\circ}$ & $\mathrm{L} \#^{\circ} \mathrm{H} \# / \mathrm{L}^{\circ}$ \\
\hline 77 & $\mathrm{~L}^{\circ} \mathrm{M} / \mathrm{L} \#^{\circ}$ & $\mathrm{L} \#^{\circ} \mathrm{M} / \mathrm{L} \#^{\circ}$ & $\mathrm{L}^{\circ} \mathrm{L} \# / / \mathrm{L}^{\circ}$ & $\mathrm{L} \#^{\circ} \mathrm{L} \# / \mathrm{L}^{\circ}$ & $\mathrm{L}^{\circ} \mathrm{L} \# / \mathrm{L \#}^{\circ}$ \\
\hline 78 & $\mathrm{~L} \#^{\circ} \mathrm{H} \# / \mathrm{L}^{\circ}$ & $\mathrm{L} \#^{\circ} \mathrm{H} \$ / \mathrm{L}^{\circ}$ & $\mathrm{L} \#^{\circ} \mathrm{H} \# / \mathrm{L}^{\circ}$ & $\mathrm{L}^{\circ} \mathrm{H} \# / \mathrm{L}^{\circ}$ & $\mathrm{L} \#^{\circ} \mathrm{H} \# / \mathrm{L}^{\circ}$ \\
\hline 79 & $\begin{array}{l}\mathrm{L} \#^{\circ} \mathrm{L} / \\
\mathrm{L} \#^{\circ} \mathrm{H} \#\end{array}$ & $\mathrm{~L}^{\circ} \mathrm{L}$ & $\mathrm{L}^{\circ} \mathrm{H} \# / \mathrm{L}^{\circ}$ & $\mathrm{L} \#^{\circ} \mathrm{H} \# / \mathrm{L}^{\circ}$ & $\mathrm{L} \#^{\circ} \mathrm{H \#} / \mathrm{L}^{\circ}$ \\
\hline 80 & $\mathrm{LM}^{\circ} \mathrm{H} \#$ & $\mathrm{LM}^{\circ} \mathrm{H} \$$ & $\mathrm{LM}^{\circ} \mathrm{H} \#$ & $\mathrm{LM}^{\circ} \mathrm{H} \#$ & $\mathrm{LM}^{\circ} \mathrm{H} \#$ \\
\hline
\end{tabular}




\begin{tabular}{|c|c|c|c|c|c|}
\hline 81 & $\begin{array}{l}\mathrm{LM}^{\circ} \mathrm{H} \# / \\
\mathrm{L}+\mathrm{MH} \#^{\circ} \mathrm{M}\end{array}$ & $\mathrm{LM}^{\circ} \mathrm{H} \$$ & $\mathrm{LM}^{\circ} \mathrm{H} \#$ & $\mathrm{LM}^{\circ} \mathrm{H} \#$ & $\mathrm{LM}^{\circ} \mathrm{H} \#$ \\
\hline 82 & $\begin{array}{l}\mathrm{LM}^{\circ} \mathrm{H} \# \text { / } \\
\mathrm{L}+\mathrm{MH}^{\circ} \mathrm{M}\end{array}$ & $\mathrm{LM}^{\circ} \mathrm{H} \$$ & $\mathrm{LM}^{\circ} \mathrm{H} \#$ & $\mathrm{LM}^{\circ} \mathrm{H} \#$ & $\mathrm{LM}^{\circ} \mathrm{H} \#$ \\
\hline 83 & $\begin{array}{l}\mathrm{LM}^{\circ} \mathrm{H} \# \text { / } \\
\mathrm{L}+\mathrm{MH} \#^{\circ} \mathrm{M}\end{array}$ & $\mathrm{LM}^{\circ} \mathrm{H} \$$ & $\mathrm{LM}^{\circ} \mathrm{H} \#$ & $\mathrm{LM}^{\circ} \mathrm{H} \#$ & $\mathrm{LM}^{\circ} \mathrm{H} \#$ \\
\hline 84 & $\begin{array}{l}\mathrm{LM}^{\circ} \mathrm{H} \# / \\
\mathrm{L}+\mathrm{MH} \#^{\circ} \mathrm{L}\end{array}$ & $\mathrm{LM}^{\circ} \mathrm{H} \$$ & $\mathrm{LM}^{\circ} \mathrm{H} \#$ & $\mathrm{LM}^{\circ} \mathrm{H} \#$ & $\mathrm{LM}^{\circ} \mathrm{H} \#$ \\
\hline 85 & $\begin{array}{l}\mathrm{LM}^{\circ} \mathrm{H} \# / \\
\mathrm{L}+\mathrm{MH}^{\circ} \mathrm{L}\end{array}$ & $\mathrm{LM}^{\circ} \mathrm{H} \$$ & $\mathrm{LM}^{\circ} \mathrm{H} \#$ & $\mathrm{LM}^{\circ} \mathrm{H} \#$ & $\mathrm{LM}^{\circ} \mathrm{H} \#$ \\
\hline 86 & $\mathrm{LM}^{\circ} \mathrm{H} \#$ & $\mathrm{LM}^{\circ} \mathrm{H} \$$ & $\mathrm{LM}^{\circ} \mathrm{H} \#$ & $\mathrm{LM}^{\circ} \mathrm{H} \#$ & $\mathrm{LM}^{\circ} \mathrm{H} \#$ \\
\hline 87 & $\begin{array}{l}\mathrm{LM}^{\circ} \mathrm{H} \# \text { / } \\
\mathrm{L}+\mathrm{MH}^{\circ} \mathrm{M}\end{array}$ & $\mathrm{LM}^{\circ} \# \mathrm{H}$ & $\mathrm{LM}^{\circ} \mathrm{H} \#$ & $\mathrm{LM}^{\circ} \mathrm{H} \#$ & $\mathrm{LM}^{\circ} \mathrm{H} \#$ \\
\hline 88 & $\mathrm{LM}^{\circ} \mathrm{H} \#$ & $\mathrm{LM}^{\circ} \mathrm{H} \$$ & $\mathrm{LM}^{\circ} \mathrm{H} \#$ & $\mathrm{LM}^{\circ} \mathrm{H} \#$ & $\mathrm{LM}^{\circ} \mathrm{H} \#$ \\
\hline 89 & $\begin{array}{l}\mathrm{LM}^{\circ} \mathrm{H} \# \text { / } \\
\mathrm{L}+\mathrm{MH} \#^{\circ} \mathrm{L}\end{array}$ & $\begin{array}{l}\mathrm{LM}^{\circ} \mathrm{H} \$ / \\
\mathrm{LM}^{\circ} \mathrm{L}\end{array}$ & $\mathrm{LM}^{\circ} \mathrm{H} \#$ & $\mathrm{LM}^{\circ} \mathrm{H} \#$ & $\mathrm{LM}^{\circ} \mathrm{H} \#$ \\
\hline 90 & $\mathrm{~L} \#^{\circ} / \mathrm{L} \#^{\circ}$ & $\mathrm{L} \#^{\circ}$ & $\mathrm{L} \#^{\circ}$ & $\mathrm{L} \#^{\circ}$ & $\mathrm{L}^{\circ}$ \\
\hline 91 & $\mathrm{~L} \#^{\circ} \mathrm{M} / \mathrm{L} \#^{\circ}$ & $\mathrm{L} \#^{\circ} \mathrm{M} / \mathrm{L} \#^{\circ}$ & $\mathrm{L}^{\circ} \mathrm{L} \# / \mathrm{L}^{\circ}$ & $\mathrm{L}^{\circ} \mathrm{L} \# / \mathrm{L}^{\circ}$ & $\mathrm{L}^{\circ} \mathrm{L} \#$ \\
\hline 92 & $\mathrm{~L} \#^{\circ} \mathrm{M} / \mathrm{L} \#^{\circ}$ & $\mathrm{L} \#^{\circ} \mathrm{M} / \mathrm{L} \#^{\circ}$ & $\mathrm{L} \#^{\circ} \mathrm{L} \# / \mathrm{L}^{\circ}$ & $\mathrm{L} \#^{\circ} \mathrm{L} \# /$ L\# & $\mathrm{L}^{\circ} \mathrm{L} \#$ \\
\hline 93 & $\mathrm{~L} \#^{\circ} \mathrm{M} / \mathrm{L} \#^{\circ}$ & $\mathrm{L} \#^{\circ} \mathrm{M} / \mathrm{L} \#^{\circ}$ & $\mathrm{L} \#^{\circ} \mathrm{M} / \mathrm{L} \#^{\circ}$ & $\mathrm{L} \#^{\circ} \mathrm{M} / \mathrm{L} \#^{\circ}$ & $\mathrm{L} \#^{\circ} \mathrm{M} / \mathrm{L} \#^{\circ}$ \\
\hline 94 & $\begin{array}{l}\mathrm{L} \#^{\circ} \mathrm{L} / \\
\mathrm{L} \#^{\circ} \mathrm{H} \#\end{array}$ & $\mathrm{~L} \#^{\circ}$ & $\mathrm{L} \#^{\circ} \mathrm{H} \# / \mathrm{L}^{\circ}$ & $\mathrm{L} \#^{\circ} \mathrm{H} \# / \mathrm{L}^{\circ}$ & $\mathrm{L} \#^{\circ} \mathrm{H} \#$ \\
\hline 95 & $\begin{array}{l}\mathrm{L} \#^{\circ} \mathrm{L} / \\
\mathrm{L} \#^{\circ} \mathrm{H} \#\end{array}$ & $\mathrm{~L} \#^{\circ}$ & $\mathrm{L} \#^{\circ} \mathrm{H} \# / \mathrm{L}^{\circ}$ & $\mathrm{L} \#^{\circ} \mathrm{H} \# / \mathrm{L}^{\circ}$ & $\mathrm{L} \#^{\circ} \mathrm{H} \#$ \\
\hline 96 & $\mathrm{~L} \#^{\circ} \mathrm{H} \# / \mathrm{L}^{\circ}$ & $\mathrm{L} \#^{\circ} \mathrm{H} \$ / \mathrm{L}^{\circ}$ & $\mathrm{L} \#^{\circ} \mathrm{H} \#$ & $\mathrm{~L} \#^{\circ} \mathrm{H} \# / \mathrm{L}^{\circ}$ & $\mathrm{L} \#^{\circ} \mathrm{H} \#$ \\
\hline 97 & $\mathrm{~L} \#^{\circ} \mathrm{M} / \mathrm{L} \#^{\circ}$ & $\mathrm{L} \#^{\circ} \mathrm{M} / \mathrm{L} \#^{\circ}$ & $\mathrm{L}^{\circ} \mathrm{L} \# / \mathrm{L}^{\circ}$ & $\mathrm{L}^{\circ} \mathrm{L} \# /$ L\# & $\mathrm{L} \#^{\circ} \mathrm{L} \#$ \\
\hline 98 & $\mathrm{~L}^{\circ} \mathrm{H} \# / \mathrm{L}^{\circ}$ & $\mathrm{L} \#^{\circ} \mathrm{H} \$ / \mathrm{L}^{\circ}$ & $\mathrm{L} \#{ }^{\circ} \mathrm{H} \#$ & $\mathrm{~L} \#^{\circ} \mathrm{H} \# / \mathrm{L}^{\circ}$ & $\mathrm{L} \#{ }^{\circ} \mathrm{H} \#$ \\
\hline 99 & $\begin{array}{l}\mathrm{L} \#^{\circ} \mathrm{L} / \\
\mathrm{L} \#^{\circ} \mathrm{H} \#\end{array}$ & $\mathrm{~L} \#^{\circ} \mathrm{L}$ & $\mathrm{L} \#^{\circ} \mathrm{H} \#$ & $\mathrm{~L} \#^{\circ} \mathrm{H} \# / \mathrm{L}^{\circ}$ & $\mathrm{L}^{\circ} \mathrm{H} \#$ / L\# \\
\hline 100 & M & M & L\# & L\# & $\mathrm{L \#}$ \\
\hline
\end{tabular}

As mentioned in $\S 2.3$, the complexities of the tone system of Yongning $\mathrm{Na}$ make it necessary to use two nonstandard symbols in addition to the International Phonetic Alphabet "tone-letters".

(i) The pound symbol \# stands for the last syllable of the unit to which it is lexically attached: thus $\# \mathrm{H}$ is a High tone that can only be realized after the last syllable of the unit to which it is lexically attached. This tone therefore does not surface in isolation. For instance, ' 7 pieces' and ' 7 plus the classifier for tools' are both realized with a Mid+Mid tone pattern in 
isolation ([şu- $\left.-\mathrm{k}^{\mathrm{h}} \mathrm{w}-1\right]$ and [şu-na-1], respectively), but their underlying tone is different, witness their behaviour when followed by the copula,

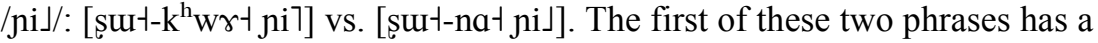
'floating' High tone (a phenomenon also observed, though less commonly, in Naxi: Michaud 2006; Michaud and He Xueguang 2007). The notation used here is: /su- $-\mathrm{k}^{\mathrm{h}} \mathrm{wr} \# 1 / \mathrm{vs} / \mathrm{su}-\mathrm{t}-\mathrm{na}-1 /$.

(ii) The dollar sign $\$$ stands for the end of the morphological nucleus. Drawing examples from the same classifiers as above, ' 6 pieces' and ' 6 plus the classifier for tools' are both realized with a Mid+High tone pattern in isolation $\left(\left[\mathrm{q}^{\mathrm{h}} \mathrm{y}-\mathrm{k}^{\mathrm{h}} \mathrm{w} \gamma\right]\right]$ and $\left.\left[\mathrm{q}^{\mathrm{h}} \mathrm{y}-\mathrm{na}\right]\right]$, respectively), but their underlying tone is different, witness their behaviour when followed by the

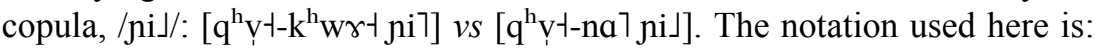

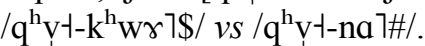

(iii) The symbol ${ }^{\circ}$ indicates the juncture between the two halves of the phrase for numerals 20 or higher, i.e. those that have an indication of a digit for tens. For instance, the indication $\mathrm{L} \mathrm{H}^{\circ} \mathrm{L}$ for the numeral ' 93 ' associated with a classifier of category $\mathrm{H} 1$ (such as $/ \mathrm{k}^{\mathrm{h}} \mathrm{w} \gamma \mathrm{7} /$ 'piece of') means that the string of syllables, in this case /gv.ts ${ }^{\mathrm{h}} \mathrm{i}$.so. $\mathrm{k}^{\mathrm{h}} \mathrm{w} \gamma /$, receives a $\mathrm{L} \#$ tone on its first half (/gv.ts ${ }^{\mathrm{h}} \mathrm{i} /{ }^{\prime} 90$ ') and a $\mathrm{L}$ tone on its second half (/so.k ${ }^{\mathrm{h}} \mathrm{w} \gamma /$ ' 3 pieces'). L\# is a Low tone that associates immediately before the last syllable (this anchoring is indicated by the \# symbol explained above); the first syllable receives $\mathrm{M}$ by default. This yields $/ \mathrm{gv}_{\mathrm{i}} \mid \mathrm{ts}^{\mathrm{h}} \mathrm{i} \mathrm{J} /$. As for the simple $\mathrm{L}$ tone of the second half, it associates to all syllables, yielding /so $J \mathrm{k}^{\mathrm{h}} \mathrm{wr} /$ and the final output $\left.\left./ g y \mid t s^{h} i\right\lrcorner s o\right\lrcorner k^{h} w \gamma J /$. For visual clarity, a hyphen is added to indicate the syntactic juncture between the numeral and classifier; $\left./ g v \mid t s^{h} i\right\rfloor s o J-k^{h} w r J /$, even though this juncture does not play any role in tone assignment.

Importantly, the juncture indicated by ${ }^{\circ}$ is internal to the tone group: it does not separate two tone groups. Numeral-plus-classifier phrases typically constitute one single tone group - although speakers can choose to split them into two groups for expressive (emphatic) purposes, as will be discussed at the beginning of section 6 .

The items in Table 2 that begin with ${ }^{\circ}$ do not have any specified tone on their first portion; that portion receives a Mid tone by default. Thus, the phrase ' 33 days' has a ${ }^{\circ} \mathrm{L}$ tone pattern: a Low tone that associates after the juncture, yielding /...so $\rfloor$ ni $\rfloor /$. Since Low tones do not spread regressively ("right-to-left"), the first portion receives $\mathrm{M}$ by default (/so-tshi-../),

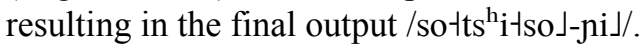


Likewise, the items that end with ${ }^{\circ}$ do not have any specified tone on their second portion. That portion receives its tones by the application of the tonal rules that govern tonal groups in Yongning Na. For instance, '40 years' has the tone pattern $\mathrm{LH}^{\circ}$ : tone $\mathrm{L \#} \mathrm{(a} \mathrm{final} \mathrm{L}$ tone) associates to the first half of the phrase, yielding /zy.tshi」.../, then /zy $\left.\mid t s^{h} i\right\rfloor . . /$ (As mentioned above, tones do not spread leftward; the first syllable receives a Mid tone by default.) At this point a tonal rule applies (see section 6 for more details): a tone cannot be surrounded by higher tones within a tone group (there are no $\left|\mathrm{M}_{L} \mathrm{M}\right|$ sequences, nor are there $\left|\mathrm{H}_{M} \mathrm{H}\right|,\left|\mathrm{H}_{L} \mathrm{M}\right|$, $\left|\mathrm{M}_{\mathrm{L}} \mathrm{MH}\right|$, and so on; the symbol I indicates the juncture between tone groups). The only possible tone on the second portion of the phrase is therefore $\mathrm{L}$. The final output is $\left.\left./ \mathrm{z}_{\mathrm{y}}-\mathrm{ts}^{\mathrm{h}} \mathrm{i}\right\rfloor-\mathrm{k}^{\mathrm{h}} \mathrm{y}\right\rfloor /$.

\subsection{How the tonal categories were brought out and labelled}

All of the classifiers in Table 1 fall into one of nine tonal categories: the nine data columns of Table 2, based on their tonal behaviour when combined with numbers. In turn, these categories were grouped into four sets on the basis of their similarities. For instance, $\mathrm{H} 1$ and $\mathrm{H} 2$ are identical except for fourteen of the numerals: \{[14..16], [18..19], 22, 32, 42, 52, 62, $72,82,92,99\}$. Finally, labels were chosen for these four sets and the nine subcategories, as explained below.

Decisive evidence for the analysis of the tones of classifiers could, in principle, come from those classifiers that correspond transparently to a noun (or verb). Only few such classifiers were observed; all bear a straightforward relationship to the corresponding noun or verb, but this does not shed light on their affiliation to one subcategory or other. The classifier for blows is $/ \mathrm{da}-1 /$; under the hypothesis made here (that its tonal category is $\mathrm{MH}$ ), the correspondence with the verb /da-1// 'to hit, to strike' looks transparent, whereas its affiliation to the subcategory MH2 within MH still requires explanation. 'Bowl' is $/ \mathrm{q}^{\mathrm{h}} \mathrm{w} \gamma-1 \mathrm{l} / \mathrm{MH}$ tone), and as a classifier it yields / $\mathrm{q}^{\mathrm{h}} \mathrm{w} \gamma-17 /$ 'bowlful' (MH1 category). 'Mountain, hill' is /ьw $\mathrm{st/}$ (M tone); as a classifier it yields /swrt/ 'heap(s) of' (M1 category); /kut//'star' yields /kut// (M2 category) as a self-classifier. 'Beam', /dzo 7/, has /dzol/ (category H1) as its self-classifier. The classifier for marketplaces and cities is /dzum7/ (category H1), and the noun 'city' has a H tone: /dzu $7 /$. On the basis of these examples, it appears that the tone category of a classifier is identical to that of its corresponding noun or verb. 
Another source of evidence could be the treatment of Chinese borrowings: it can be assumed that the tone subcategories used to accommodate recent borrowings are productive in synchrony. However, only one borrowing was observed: /tcit $1 /$ for 'pound (weight unit)'. As expected, its tonal category is MH1, i.e. the majority category for classifiers with a $\mathrm{MH}$ tone, but it would be unreasonable to draw general conclusions from this isolated example.

In the absence of decisive evidence from either of these two sources, the choice of labels for the nine categories brought out by distributional analysis was guided by structural hints. The tone of the classifiers after ' 6 ' and ' 8 ' is not highly informative, since almost all tonal oppositions are neutralized in this context (the only tones that are observed are $\mathrm{H \#}$ and $\mathrm{H} \$$ ). Likewise, in phrases involving ' 3 ' and ' 10 ', only two patterns are observed. After ' 4 ' and ' 5 ', four groups can be distinguished; but if these patterns were indicative of the classifiers' lexical tone, the system would only contain two High tones (\#H and $\mathrm{H \#}$ ) and two $\mathrm{L}$ tones ( $\mathrm{L} \#$ and $\mathrm{L}$ ). There would be no Mid tones, and no contours. This would be completely unlike the lexical tones of the other monosyllabic nouns found in Yongning $\mathrm{Na}$, which consist of: H, M, L, and two types of rising contours, analyzed as $\mathrm{MH}$ and LM.

On the other hand, the tone patterns in association with the numerals ' 1 ' and ' 2 ' make good sense as labels for tonal categories: these four patterns are $\mathrm{H}, \mathrm{MH}, \mathrm{M}$ and $\mathrm{L}$, all of which exist as lexical tones for nouns. They are therefore adopted, adding a numeral to distinguish the subcategories (two for $\mathrm{H}, \mathrm{MH}$ and $\mathrm{M}$, and three for $\mathrm{L}$ ), by order of decreasing frequency (e.g. there are more classifiers in category M1 than M2).

These labels also make sense under the (admittedly simplistic) assumption that the contribution made by the tone of the classifier will be reflected statistically in the tone pattern of the numeral-plus-classifier phrase. Averaging over the entire range of tone patterns from the number 1 to the number 100 , the categories that have a High tone after ' 1 ' and ' 2 ' (labelled $\mathrm{H} 1$ and $\mathrm{H} 2$ in Table 2) are also those with the highest proportion of $\mathrm{H}$ tones (either on their own: $\mathrm{H \#}, \# \mathrm{H}, \mathrm{H} \$$, or as part of a $\mathrm{MH}$ or $\mathrm{MH \#}$ contour) and the lowest proportion of L tones. Conversely, the categories that have a Low tone after ' 1 ' and '2' (labelled L1, L2 and L3 in Table 2) have the lowest proportion of $\mathrm{H}$ tones and the highest of $\mathrm{L}$ tones. The other two subgroups (M1 and M2; and MH1 and MH2) are between these two extremes; again as predicted, M1 and M2 have a higher proportion of M tones, and a lower proportion of $\mathrm{H}$ tones, than $\mathrm{MH} 1$ and $\mathrm{MH} 2$. These rule- 
of-thumb comparisons, which do not carry demonstrative value, are simply mentioned to convey a feel for the overall outlook of the data. Another indirect way of approaching these data consists of examining the occasional mistakes made by the consultant: this is one of the benefits of having an extensive set of recordings at hand.

\subsection{About mistaken realizations in the recordings}

As was mentioned earlier, the task of realizing long sequences of numeralplus-classifier phrases was challenging for the consultant. Among the 2,810 tokens, $7 \%$ have a mistaken tone pattern: ${ }^{i}$ a tone pattern which the consultant (F4) consistently judged to be incorrect (a tonal slip of the tongue) when we returned to the data after recording sessions.

Under the hypothesis that these mistakes reflect in part the phonological complexity of the tone patterns at issue, their distribution can shed some light on which parts of the system are more complex. (The notion that mistakes may provide insights about language dates back at least to Henri Frei's La grammaire des fautes [1929]; see also Fromkin 1973 and Rossi and Peter-Defare 1998, among others.)

Table 3 shows the distribution of mistakes as a factor of the range of tens: how many of the observed mistakes concern numerals between 1 and 9 (leftmost bar), 10 and 19 (second bar), etc. Table 4 shows the distribution of mistakes as a factor of the last digit (units): how many mistakes concern numbers ending in ' 1 ', in ' 2 ', etc.

The data are not symmetrical enough for a full-fledged statistical treatment. In particular, (i) there are more data for some tonal categories than others, (ii) some combinations have several repetitions, and (iii) there are slightly more data in the range [1..10] than for higher numerals. 
Table 3. Number of mistakes in the recorded numeral-plus-classifier phrases as a factor of the range of tens.

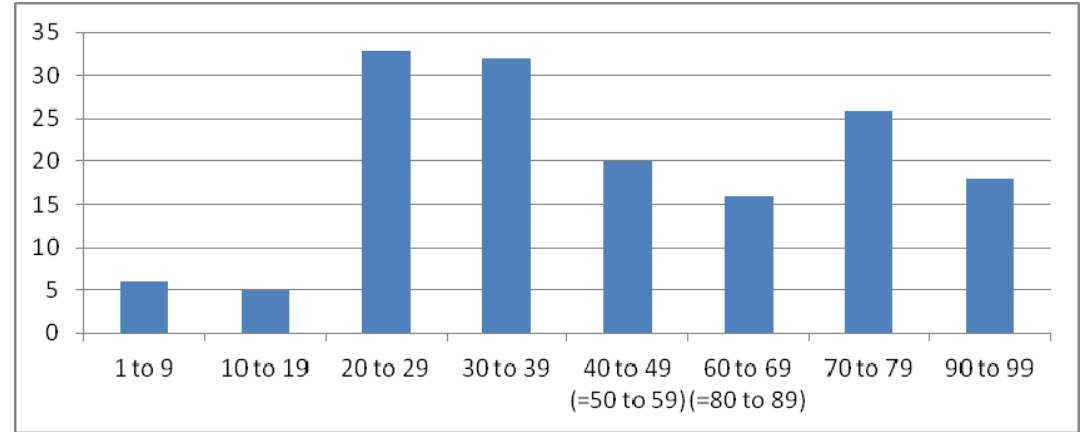

Table 4. Number of mistakes in the recorded numeral-plus-classifier phrases as a factor of the last digit (units).

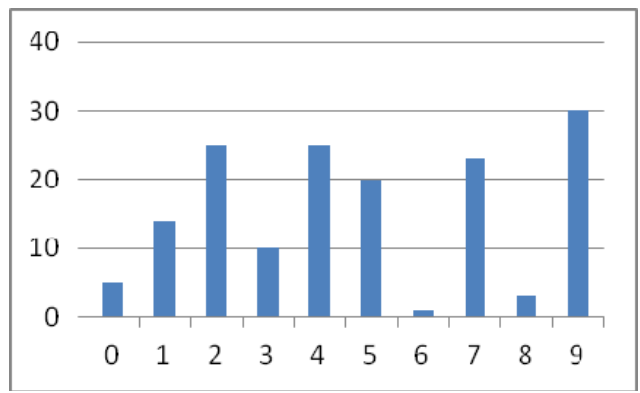

The numerals ending in '6' and '8' (e.g. '6', '16', '26'; '8', '18', '28') are noticeably less subject to mistakes, and those beginning in these figures (e.g. '60', '61', '62', '63', '89') are also slightly less often mispronounced than neighbouring "numeral-runs". Numerals ending in ' 6 ' and ' 8 ' are also the least complex, many tonal distinctions being neutralized after these numerals. Those ending in '7' and '9', which according to the consultant's intuition are the most difficult, are indeed among the most frequently mistaken, although ' 7 ' does not stand out within the top half of the list of mistakes, which includes $\{2,4,5,7,9\}$. 


\section{Discussion}

\subsection{About variants of the tone patterns}

No observed numeral-plus-classifier phrase has more than two acceptable variants for its tone pattern. Many of the variants can be explained in light of general rules which hold within a tone group in Yongning Na: if the numeral-plus-classifier phrase is treated as one single tone group, then these rules apply, and modify the tone pattern. The rules are the following:

(i) all tones following a $\mathrm{H}$ tone are lowered to $\mathrm{L}$ ( $\mathrm{H}$ tone is culminative);

(ii) if a tone group only has $\mathrm{L}$ tones, a post-lexical $\mathrm{H}$ tone is added to its last syllable, creating a contour; ${ }^{3}$

(iii) a tone cannot be surrounded by higher tones within a tone group: there are no $\left|\mathrm{MLM}_{\mathrm{L}}\right|$ sequences, nor are there $\left|\mathrm{H}_{\mathrm{M}} \mathrm{H}\right|,\left|\mathrm{H}_{\mathrm{LM}}\right|$, $\left|\mathrm{M}_{\mathrm{L}} \mathrm{MH}\right|$, and so on. (Note that the juncture between tone groups is indicated by the symbol $\mathrm{I}$; this juncture is indicated in the transcription of the narratives available online).

For instance, in the case of ' 44 ' plus the classifier for tools, /nat/ (category M1), the phrase /zy $1 t \mathrm{ts}^{\mathrm{h}} \mathrm{i} \mathrm{z}_{\mathrm{y}} \dashv-\mathrm{na} \mathrm{7} /$ is not a well-formed tone group, since it is not in keeping with rule (iii) above: the $\mathrm{L}$ tone on $/ \mathrm{ts}^{\mathrm{h}} \mathrm{i} / /$ is surrounded by higher tones. This syntactic phrase is therefore to be analyzed as consisting of two tone groups: /zy $\left.\dashv \mid \mathrm{ts}^{\mathrm{h}} \mathrm{i}\right\rfloor \mid \mathrm{z} \mathrm{y}-\mathrm{na} \mathrm{T} /$ (tone pattern: $\mathrm{L} \#^{\circ} \mathrm{H \#}$ ). If this phrase were treated as one single tone group, the tones of its last two syllables would be lowered to L. This is precisely what happens in the tonal variant that is attested for this phrase: /zy $\left.\left.\dashv t^{\mathrm{h}} \mathrm{i}\right\lrcorner \mathrm{zy}_{\mathrm{y}}\right\rfloor \mathrm{na} /$ / (tone pattern: $\mathrm{L}^{\circ}$ ). The two variants can therefore be described as (i) a form consisting of two tone groups, and (ii) a simplified form, whose tonal pattern results straightforwardly from its treatment as a single tone group.

The same applies to all tonal patterns in the range [40..59], [70..79] and [90..99], since the first two syllables (corresponding to ' 40 ', ' 50 ', ' 70 ' and '90' respectively) have a Mid-plus-Low pattern. This pattern precludes any tone other than $\mathrm{L}$ on the following syllables within the same tone group (since that would not be in keeping with rule (iii) above). One would

3 This post-lexical tone was described as $\mathrm{M}$ in my first study of this topic, Michaud 2008; there is in fact no opposition between LM and $\mathrm{LH}$, and it may be more appropriate to describe the postlexical tone as $\mathrm{H}$. 
therefore expect all of these combinations to have two variants. This holds true as a general rule: when the consultant indicated a complex form and I tried substituting a simplified form, that form was never rejected by the consultant. On the other hand, for some combinations the simpler form is the only acceptable one: for instance, for ' 44 ' with a classifier of category $\mathrm{M} 2$, such as /lut// (the classifier for round objects), one has to say

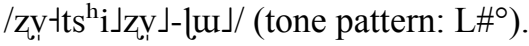

Supposing, on the analogy of category M1, that $\left./ *_{z y}-t t^{h} i\right\rfloor \mid z v--\lfloor u\rceil /$ was acceptable in an earlier state of the language, it must be supposed to have fallen out of use; this is in keeping with the expected preference for simpler forms in language evolution. For category M1, where there are currently two variants in common use, the consultant's intuition is that the complex variant, /zy $\left.-t^{\mathrm{h}} \mathrm{i}\right\rfloor \mid \mathrm{zy}-\mathrm{na} 7 /$, is somewhat "slow" and "clumsy": in discourse, it conveys special emphasis and is only appropriate as part of an expressive strategy to draw attention to the figure at issue. To sum up, the integration of numeral-plus-classifier phrases into one single tone group is the general rule.

Interestingly, when a phrase ends in two Low-tone syllables, it is possible to test whether these Low tones result from the levelling down of originally non-Low tones (as in the case of /zy above) or reflect an underlying Low tone. In the latter case, it is possible to divide the phrase into two tone groups; the second group, having an underlying $\mathrm{L}$ tone, receives a postlexical final $\mathrm{H}$ tone, by the application of rule (ii) (mentioned above). For example, '23 years' (category MH1) can be

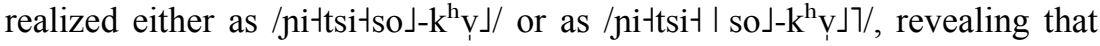
its underlying tone pattern is $\mathrm{M}^{\circ} \mathrm{L}$, whereas with the classifier for tools it would be incorrect to say $\left.\left.\left./{ }^{*} \mathrm{zy}_{\mathrm{y}}-\mathrm{tsh}^{\mathrm{h}} \mathrm{i}\right\rfloor \mid \mathrm{zy}\right\rfloor-\mathrm{na}\right\lrcorner 7 /$ : the variant with a division into two groups is $\left./ z_{y}-1 s^{h} i\right\rfloor \mid z y-n a 7 /$. This explains neatly why the contour-creating final $\mathrm{H}$ tone is only allowed for some of the phrases. A device for forcing the division of the phrase into two tone groups consists of inserting the syllable /la/, 'and', before the last digit: e.g. /sultsh $\mathrm{i}\lrcorner$-la」। $q^{\text {h }} \mathrm{v}^{-}-\mathrm{s} w \gamma 7 /$ '79 heaps'.

\subsection{About regularity and irregularity}

The system as presented in Table 2 is regular and productive, in that all the classifiers of a given tone category have the same tone patterns. As it lends itself straightforwardly to computer implementation, a simple Perl script 
was written (available from the author). It takes as its input the classifier's tone category and segmental composition and a numeral (or range of numerals) from 1 to 100. The data in Table 2 are stored within the script, allowing for the tone pattern to be recovered through table lookup. The surface-phonological tone pattern is then assigned to the phrase on the basis of the general principles governing tone assignment in $\mathrm{Na}$ (which are encoded into the script), such as that simple $\mathrm{L}$ and $\mathrm{M}$ tones attach to all the syllables within their domain, tone sequences attach to syllables left-toright, and so on. For instance, providing as input the segments $/ \mathrm{na} /$, the tonal category $\mathrm{M} 1$, and the numeral ' 44 ', the script yields the following output:

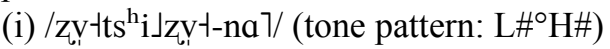

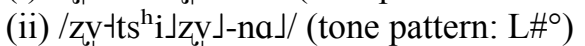

In the present version of the script, all of the information set out in Table 2 is encoded in full, specifying the tone patterns of 900 combinations (9 tone categories of classifiers times 100 numerals); this makes computer implementation simple, but is uneconomical from the point of view of linguistic modelling. The addition of some rules could significantly reduce the number of combinations that need to be indicated. In particular, the tone patterns of [40..49] are identical with those of [50..59]; likewise for [60..69] and [80..89]. Numerals ending in ' 1 ' also have identical patterns with those ending in ' 2 ', with a few exceptions in category $\mathrm{H} 2$. The information provided for each subcategory (H1 and H2, M1 and M2, and so on) could also be simplified by considering one of the subcategories as the norm, and only supplying the forms for the other subcategories where they differ from that norm.

However, it is clear that even after this simplification task has been conducted, large numbers of tonal patterns will still need to be specified individually. For instance, neither $\mathrm{H} 1$ nor $\mathrm{H} 2$ can be considered as a simplified version of the other: while the systematic application of a $\mathrm{L}$ tone to all the phrases from ' 10 ' to ' 19 ' suggests that $\mathrm{H} 2$ is a simplified version of the patterns of $\mathrm{H} 1$, the presence of different tones after numerals ending in ' 1 ' and ' 2 ' is a complexity found for $\mathrm{H} 2$ and not for $\mathrm{H} 1$. The latter observation is a striking counterexample to the "pan-Naish" generalization that the numerals ' 1 ' and ' 2 ' always have the same tone patterns - a generalization which holds for Naxi and Laze, and for all the rest of the $\mathrm{Na}$ data. One case of idiosyncratic tone pattern was observed: /to $7 /$ 'armful' belongs to the $\mathrm{H} 1$ category, but the combination ' 11 armfuls' is realized as $/ \mathrm{ts}^{\mathrm{h}} \mathrm{e}-\mathrm{d}$ wu-to-t/ instead of the expected $\left.\left./ \mathrm{ts}^{\mathrm{h}} \mathrm{e}\right\rfloor \mathrm{du}\right\rfloor-$ to $J /$. 
The tone patterns of numeral-plus-classifier phrases can therefore be considered part of the language's irregular morphotonology: tone patterns which can be accounted for neither by sandhi nor regular morphotonological rules. Guillaume Jacques (p.c.) notes that irregular morphology in $\mathrm{Na}$, as also in other Naish languages, as well as in Yi and Pumi, largely consists of irregular morphotonology. This system may appear staggeringly complex; however, numeral-plus-classifier phrases are extremely frequent in discourse, a factor which is known to favour the preservation of irregular morphology.

\section{Conclusion}

Few speakers nowadays still master the complex tone patterns studied here, which could be included in the open list of "endangered phonemic oppositions" drawn in Michaud and Latami Dashi (2011). While the type of complexity found in Yongning $\mathrm{Na}$ is not as spectacular as that found in the Ahmao language (Hmong-Mien family), where classifiers have "12 basic forms, each displaying a complex cluster of meanings" (Gerner and Bisang 2009), the $\mathrm{Na}$ data may nonetheless have a contribution to make to typological generalizations, showing that the tones of classifiers can be more complex than those of nouns (in Na: 9 tonal categories for classifiers, versus 5 for monosyllabic nouns).

Finally, from a language-specific point of view, while the synchronic picture can now be considered to be relatively well documented, there remains a long way to go to understand the evolution that shaped it.

\section{Notes}

i This figure includes some items that were deleted from the sound files at an early stage of the study, before the principle of preserving the recordings unchanged was adopted. 
Published in: Nathan Hill \& Tom Owen-Smith (eds.), Transhimalayan Linguistics. Berlin: De Gruyter Mouton (2013), pp. 275-311.

\section{References}

Abramson, Arthur S. 1979. The coarticulation of tones: An acoustic study of Thai. In Therapan L. Thongkum, V. Panupong, P. Kullavanijaya \& Kalaya Tingsabadh (eds.), Studies in Tai and Mon-Khmer phonetics and phonology in honor of Eugénie J.A. Henderson, 1-9. Bangkok:

Chulalongkorn University Press.

Baken, R.J. 1992. Electroglottography. Journal of Voice 6(2). 98-110.

Baxter, William H. 2000. An Etymological Dictionary of Common Chinese Characters [Preliminary draft of 28 October 2000]. http://wwwpersonal.umich.edu/ $\sim$ wbaxter/etymdict.html.

Brunelle, Marc, Nguyễn Khắc Hùng \& Nguyễn Duy Dương. 2010. A Laryngographic and Laryngoscopic Study of Northern Vietnamese Tones. Phonetica 67(3). 147-169.

Chao Yuen-ren. 1930. A system of tone letters. Le Maître phonétique 45. 24-27.

Chao Yuen-ren. 1968. A Grammar of Spoken Chinese. Berkeley/Los Angeles: University of California Press.

Ding, Picus Sizhi. 2006. A typological study of tonal systems of Japanese and Prinmi: Towards a definition of pitch-accent languages. Journal of Universal Language 7. 1-35.

Evans, Jonathan. 2008. "African" tone in the Sinosphere. Language and Linguistics 9(3). 463-490.

Fabre, Philippe. 1957. Un procédé électrique percutané d'inscription de l'accolement glottique au cours de la phonation: glottographie de haute fréquence. Bulletin de l'Académie Nationale de Médecine 141. 66-69.

François, Alexandre. 2000. L'illusion des classificateurs. Faits de langues 14. $165-175$.

Frei, Henri. 1929. La grammaire des fautes : introduction à la linguistique fonctionnelle, assimilation et différenciation, brièveté et invariabilité, expressivité. Bellegarde: Société anonyme des arts graphiques de France.

Fromkin, Victoria A. 1973. Speech errors as linguistic evidence. Berlin: Walter de Gruyter. 
Gandour, Jack \& Siripong Potisuk. 1992. Tonal coarticulation in Thai disyllabic utterances: a preliminary study. Linguistics of the Tibeto-Burman Area 15(1). 93-110.

Gerner, Matthias \& Walter Bisang. 2009. Inflectional classifiers in Weining Ahmao: Mirror of the history of a people. Folia Linguistica Historica 30(1). 183-218.

Gsell, René. 1985. Hauteurs spécifiques, types consonantiques et tons statiques en thai. In Ratanakul Suriya, David Thomas \& Premsrirat Suwilai (eds.), Southeast Asian Linguistic Studies presented to André-G. Haudricourt, 389-427. Bangkok: Mahidol University.

Guo Dalie 郭大烈 \& He Zhiwu 和志武. 1994. Naxizu Shi 纳西族史 [A History of the Naxi people]. Chongqing: Sichuan Minzu Chubanshe.

Henderson, Eugénie J.A. 1997. Bwe Karen dictionary. London: School of Oriental and African Studies, University of London.

Henrich, Nathalie, Christophe d'Alessandro, Michèle Castellengo \& Boris Doval. 2004. On the use of the derivative of electroglottographic signals for characterization of non-pathological voice phonation. Journal of the Acoustical Society of America 115(3). 1321-1332.

Hu Mingyang 胡明扬. 1997. “Q̄î, bā” biàndiào bùyí zài tuīxíng “七、八” 变调不宜再推行 [Tone sandhi for "seven" and “eight" is not suitable for promotion anymore]. Yuwen Jianshe 语文建设 6. 10 .

Huang Bufan 黄布凡. 2009. Muli Shuitianhua Gaikuang 木里水田话概况 [A survey of Muli Shuitian]. Journal of Sino-Tibetan Linguistics (Hanzangyu Xuebao) 3. 30-55.

Hyman, Larry M. \& Kenneth VanBik. 2002. Tone and stem2 formation in Hakha Lai. Linguistics of the Tibeto-Burman Area 25. 113-121.

Hyman, Larry M. \& Kenneth VanBik. 2004. Directional rule application and output problems in Hakha Lai tone. Language and Linguistics, Taipei: Academia Sinica, Special Issue: Phonetics and Phonology 5. 821-861.

Jacques, Guillaume. 2011. Tonal alternations in the Pumi verbal system. Language and Linguistics 12(2). 359-392.

Jacques, Guillaume \& Alexis Michaud. 2011. Approaching the historical phonology of three highly eroded Sino-Tibetan languages: Naxi, Na and Laze. Diachronica 28(4). 468-498. 
Lidz, Liberty. 2006. A synopsis of Yongning Na (Mosuo) [long version of handout]. 39th International Conference on Sino-Tibetan Languages and Linguistics. University of Washington, Seattle.

Lidz, Liberty. 2010. A descriptive grammar of Yongning Na (Mosuo). Austin: University of Texas, Department of linguistics. https://repositories.lib.utexas.edu/bitstream/handle/2152/ETD-UT-2010-122643/LIDZ-DISSERTATION.pdf.

Lindblom, B. 1990. Explaining phonetic variation: a sketch of the H\&H theory. In W.J. Hardcastle \& Alain Marchal (eds.), Speech production and speech modelling, 403-439. Dordrecht: Kluwer.

Michailovsky, Boyd, Alexis Michaud \& Séverine Guillaume. 2011. A simple architecture for the fine-grained documentation of endangered languages: the LACITO multimedia archive. Keynote speech at OrientalCOCOSDA 2011, Hsinchu, Taiwan, October 26th-28th 2011.

http://halshs.archives-ouvertes.fr/halshs-00620893/

Michaud, Alexis. 2004. A Measurement from Electroglottography: DECPA, and its Application in Prosody. In Bernard Bel \& Isabelle Marlien (eds.), Speech Prosody 2004, 633-636. Nara, Japan.

Michaud, Alexis. 2006. Tonal reassociation and rising tonal contours in Naxi. Linguistics of the Tibeto-Burman Area 29(1). 61-94.

Michaud, Alexis. 2008. Phonemic and tonal analysis of Yongning Na. Cahiers de linguistique - Asie Orientale 37(2). 159-196.

Michaud, Alexis. 2009. Muli Shuitianhua Shengdiao Xitong Yanjiu 木里水 田话声调系统研究 [The prosodic system of Muli Shuitian (Laze)]. (Minzu Yuwen 民族语文 [Minority Languages of China] 6. 28-33.

Michaud, Alexis. 2011. The tones of numerals and numeral-plus-classifier phrases: on structural similarities between Naxi, $\mathrm{Na}$ and Laze. Linguistics of the Tibeto-Burman Area 34(1). 1-26.

Michaud, Alexis \& He Xueguang. 2007. Reassociated tones and coalescent syllables in Naxi (Tibeto-Burman). Journal of the International Phonetic Association 37(3). 237-255.

Michaud, Alexis \& Guillaume Jacques. 2012. The phonology of Laze: phonemic analysis, syllabic inventory, and a short word list. Yuyanxue Luncong 语言学论丛 45. 196-230. 
Michaud, Alexis \& Latami Dashi. 2011. A description of endangered phonemic oppositions in Mosuo (Yongning Na). In Tjeerd De Graaf, Xu Shixuan \& Cecilia Brassett (eds.), Issues of language endangerment, 5571. Beijing: 知识产权出版社 [Intellectual property publishing house].

Michaud, Alexis, Andrew Hardie, Séverine Guillaume \& Martine Toda. 2012. Combining documentation and research: Ongoing work on an endangered language. In Xiong Deyi, Eric Castelli, Dong Minghui \& Pham Thi Ngoc Yen, (eds.), Proceedings of IALP 2012 (2012 International Conference on Asian Language Processing), 169-172. Hanoi, Vietnam: MICA Institute, Hanoi University of Science and Technology.

Orlikoff, Robert F. 1998. Scrambled EGG: The uses and abuses of electroglottography. Phonoscope 1(1). 37-53.

Pinson, Thomas M. 1998. Naxi-Chinese-English glossary, with English and Chinese indexes. Dallas: The Summer Institute of Linguistics.

Rossi, Mario \& Évelyne Peter-Defare. 1998. Les lapsus, ou, Comment notre fourche a langué. Paris: Presses universitaires de France.

Xu Yi. 1997. Contextual tonal variations in Mandarin. Journal of Phonetics 25. 61-83.

$\mathrm{Xu}$ Yi. 1998. Consistency of tone-syllable alignment across different syllable structures and speaking rates. Phonetica 55. 179-203.

$\mathrm{Yu}$, Kristine. 2010. Representational maps from the speech signal to phonological categories: a case study with lexical tones. UCLA Working Papers in Linguistics 15. 1-30. 